\title{
4-IPP, a selective MIF inhibitor, causes mitotic catastrophe in thyroid carcinomas
}

\author{
Luca Varinelli', Dario Caccia', Chiara C Volpi ${ }^{2}$, Claudio Caccia ${ }^{4}$, Maida De Bortoli', \\ Elena Taverna', Ambra V Gualeni ${ }^{2}$, Valerio Leoni ${ }^{4}$, Annunziata Gloghini ${ }^{2}$, \\ Giacomo Manenti ${ }^{3}$ and Italia Bongarzone ${ }^{1}$ \\ ${ }^{1}$ Proteomics Laboratory, Department of Experimental Oncology and Molecular Medicine, ${ }^{2}$ Department of \\ Diagnostic Pathology and Laboratory Medicine, and ${ }^{3}$ Department of Predictive and Preventive Medicine, \\ Fondazione IRCCS Istituto Nazionale dei Tumori, Via Amadeo 42, 20133 Milan, Italy \\ ${ }^{4}$ Laboratory of Clinical Pathology and Medical Genetics, Fondazione IRCCS 'Carlo Besta' Istituto Neurologico, \\ Via Amadeo 42, 20133 Milan, Italy
}

\author{
Correspondence \\ should be addressed \\ to I Bongarzone \\ Email \\ italia.bongarzone@ \\ istitutotumori.mi.it
}

\begin{abstract}
Macrophage migration inhibitory factor (MIF) is a pro-inflammatory cytokine that is over-expressed in several human neoplastic cells. When MIF binds its receptor (CD74) and co-receptor (CD44), it initiates signaling cascades that orchestrate cell proliferation and survival, and it can directly modulate the activity of AMPK. These activities indicate that MIF potentially regulates cell survival and metabolism. We found that MIF was primarily co-expressed with CD74 in 16 out of 23 papillary thyroid carcinoma (PTC) and in all the 27 available anaplastic thyroid carcinoma (ATC) biopsy samples. MIF and CD74 were co-expressed in TPC-1 and HTC-C3 cell lines. The selective MIF inhibitor, 4-iodo-6phenylpyrimidine (4-IPP), blocked MIF/CD74 internalization, activated JNK, and dosedependently inhibited proliferation inducing apoptosis and mitotic cell death. In two CD74-negative cell lines, NIM-1 and K1, 4-IPP treatment partially reduced proliferation. Coordinated MIF and CD74 expression appeared to confer in tumor cells the plasticity necessary to escape cell cycle regulation, metabolic changes, and stress conditions. MIF/CD74 signaling removal made cells susceptible to apoptosis and mitotic cell death. This finding suggests a possible avenue for targeting DNA endoreduplication, thus preventing the proliferation of therapy-resistant cell subpopulations. This study highlights MIF/CD74 axis as an important player in the biology of aggressive thyroid neoplasms.
\end{abstract}

Key Words
- papillary thyroid carcinoma
- anaplastic thyroid carcinoma
- macrophage migration
inhibitory factor
- CD74
- 4 -IPP
- AMPK
- endoreduplication

Endocrine-Related Cancer (2015) 22, 759-775

\section{Introduction}

Macrophage migration inhibitory factor (MIF), a pleiotropic cytokine with inflammatory function and oxidoreductase activity, plays an essential role in both innate and adaptive immune responses. MIF antagonizes glucocorticoid immunosuppression, and it is implicated in the production of tumor necrosis factor $\alpha$ (TNF $\alpha$ ) and nitric oxide (Bucala 2013). MIF also plays a role in cellular responses to DNA damage and cell cycle regulation (Nemajerova et al. 2007), and it affects glucose homeostasis through various pathways (Toso et al. 2008). MIF has been implicated in several disease conditions, including rheumatoid arthritis (Morand et al. 2006) sepsis (Calandra \& Roger 2003), diabetes (Sánchez-Zamora \& RodriguezSosa 2014), and cancer (Candido \& Hagemann 2013).

Published by Bioscientifica Ltd 
In cancer, MIF promotes growth, cell cycle progression, and angiogenesis. MIF signaling is mediated by interacting with CD74, a single-pass, type II membrane receptor, also known as the MHC class II chaperone invariant chain (Sanchez-Niño et al. 2013). MIF binding to the extracellular domain of CD74 stimulates rapid, sustained activation of ERK-MAP signaling (Leng et al. 2003), phosphatidylinositol-3/protein kinase B (PI3K/AKT) signaling (Lue et al. 2007), and Src signaling through CD44 recruitment (Shi et al. 2006). MIF binding to the CD74/CD44 complex regulates cell survival and proliferation by inhibiting apoptosis and activating prostaglandin $\mathrm{E}_{2}$ production in a variety of cell types (Startlets et al. 2006). In some immune processes, MIF acts as a non-cognate ligand of chemokine receptors, CXCR2 and CXCR4. Biochemical evidence suggests that, upon MIF stimulation, these receptors may act as additional, signal-transducing CD74 co-receptors (Klasen et al. 2014).

Recent findings indicated that MIF binding to CD74 stimulated heart and muscle glucose uptake, and that the autocrine/paracrine effects of endogenous cardiac MIF contributed to AMP-activated protein kinase (AMPK) activation and glucose uptake during ischemia (Wang et al. 2014). Moreover, MIF can operate intracellularly in protein-protein interactions with proteins that modulate the intracellular redox state (Thiele \& Bernhagen 2005) and with several key proteins that govern the cell cycle. MIF antagonizes Jab1-dependent cell-cycle control by regulating the Skp1-Cullin-1-F-box (SCF) ubiquitin E3 ligase complex, which coordinates ubiquitin-mediated destruction of two inhibitors of cyclin-dependent kinases, cyclins p21 and p27 (Fingerle-Rowson \& Petrenko 2007). Additionally, through a mechanism not fully understood, MIF inhibition of Jab1 also negatively modulates the JNK-mediated stress response (Kleemann et al. 2000).

Papillary thyroid cancer outcomes are generally favorable, but up to $30 \%$ of patients relapse after an initial treatment with curative intent, and $15 \%$ die from the disease (Kloos 2005). Surgery and radioactive iodine therapy effectively treat the majority of cases. However, effective options for systemic therapy are limited in patients with advanced, unresecatable, radioiodine-refractory thyroid cancer. Novel therapeutic approaches are required to treat anaplastic and poorly differentiated thyroid carcinoma, which are often resistant to current available therapies. Treatments for advanced thyroid cancer will require more insight into thyroid carcinogenesis (Kojic et al. 2011).

In this study, we show the elevated expression of MIF and CD74 in papillary and anaplastic thyroid cancer samples and cell lines. By in vitro experiments using cell lines we observed that 4-iodo-6-phenylpyrimidine (4-IPP) perturbation of MIF/CD74 axis coincided with the loss of signaling pathways that regulate salvage pathways of endoreduplicated/tetraploid cells. A caveat of these effects is that MIF/CD74 positive cell lines were a mixture of diploid and tetraploid cells. Targeting tetraploid cancer cells is an important goal, particularly given the potential involvement of these cells in tumor progression, therapy resistance, and aneuploidy. Our data support that MIF/CD74 signaling pathway may represent a potential therapeutic target for patients with anaplastic thyroid carcinoma (ATC).

\section{Materials and methods}

\section{Cell culture and drug treatment}

The papillary thyroid carcinoma (PTC)-derived cell lines, TPC-1, NIM-1, K1, and B-CPAP were obtained from America Type Culture Collection (ATCC, Rockville, MD, USA). The ATC-derived cell line, HTC-C3 was obtained from Riken Gene Bank (RGB, Koyadai, Tsukuba Science City, Japan). Cell lines were authenticated by the Fragment Analysis Facility at Istituto Nazionale dei Tumori, Milan, Italy, with the StemElite ID System (Promega). The short tandem repeat (STR) DNA profile was matched to the original DNA profile in the cell line, as previously described (Schweppe et al. 2008). Cells were routinely tested for mycoplasma. TPC-1, NIM-1, B-CPAP and HTC-C3 cells were grown in DMEM (Gibco) supplemented with 10\% fetal bovine serum (FBS; HyClone Laboratories, Logan, UT, USA) and $1 \mathrm{mM}$ sodium pyruvate. K1 cells were grown in DMEM: Ham'sF12:MCDB (2:1:1) (Gibco) supplemented with 10\% FBS (HyClone Laboratories). For cell treatments, $88.5 \mathrm{mM}$ of 4-IPP (Calbiochem) in 100\% DMSO was diluted directly in the cell culture medium to achieve the working concentrations. The final solvent concentration was $<0.1 \%$ for all samples, including controls.

For immunochemistry, TPC-1 and NIM-1 cell lines were treated with the following antibodies: anti-CD74, anti-MIF (Abcam, Inc., Cambridge, UK), and an antimouse IgG1 (Sigma-Aldrich) as control. The antibodies were diluted directly in the cell culture medium to achieve the working concentrations. In all experiments, cell lines have been used at passage five and maintained in culture until the twentieth passage.

\section{Proliferation assay and immunofluorescence}

The sulforhodamine B (SRB) proliferation assay (SigmaAldrich) and immunofluorescence experiments were

Published by Bioscientifica Ltd 
performed as previously described (Caccia et al. 2010). PTC and ATC cells were stained with fluorescent phalloidin (Sigma-Aldrich) for visualizing the cytoskeleton, with diamidino-2-phenylindole (DAPI) (Biostatus Limited, Leicestershire, UK) as a nuclear marker, with anti- $\beta$-tubulin (Sigma-Aldrich) for visualizing microtubules organization and with anti-phospho-histone H3 (S10) (Abcam, Inc.) for visualizing histone H3. Slides were imaged with immunofluorescence microscopy (Eclipse E1000; Nikon Instruments, Inc., NY, USA).

\section{FACS analysis}

PTC cell lines (TPC-1 and K1) were seeded on 100-mm tissue culture plates, incubated for $18 \mathrm{~h}$, then treated with drugs for $0,12,24,48$, or $72 \mathrm{~h}$. Next, FACS analysis was performed as previously described (Caccia et al. 2010).

\section{Sample preparation, SDS-PAGE, and immunoblotting}

PTC and ATC cell lines (TPC-1, K1, NIM-1, B-CPAP and HTC-C3) were seeded at $12.5 \times 10^{4}$ cells $/ \mathrm{cm}^{2}$, cultured for $18 \mathrm{~h}$, and exposed to drugs for the times indicated. Cell pellets were solubilized as previously described (Caccia et al. 2010). Normal, papillary and anaplastic frozen tissue samples $(\sim 50 \mathrm{mg})$ were homogenized and solubilized as previously described. Protein concentrations were determined with the bicinchoninic acid (BCA) assay (Bio-Rad Laboratories). Protein separation by electrophoresis (SDS-PAGE) and electroblotting were performed as previously described (Gorla et al. 2009) western blot quantifications were performed using Quantity one software (Bio-Rad).

\section{Tissue specimens}

Thyroid samples were collected at the Deparment of Pathology at Fondazione IRCCS Istituto Nazionale dei Tumori, Milano (INT). The PTCs $(n=23)$ and ATCs $(n=27)$ were classified according to WHO Classification (Delellis et al. 2004). The non-neoplastic thyroid tissues $(n=27)$ were from patients with pathologies other than thyroid tumors. The study was performed in accordance with the Declaration of Helsinki Principles.

\section{Immunohistochemistry}

Immunohistochemistry was performed with $3-\mu \mathrm{m}$, formalin-fixed, paraffin-embedded tissue sections. Tissues were stained with hematoxylin eosin or probed with mouse MAB against CD74 (LN2; diluted 1:100; Abcam, Inc.) and against MIF (4E4; diluted 1:200; Abcam, Inc.). Immunohistochemistry was performed with an automated immunostainer (BenchMark Ultra, Ventana Medical Systems, Inc., Tucson, AZ, USA) according to the manufacturer's instructions.

\section{Feulgen reaction}

Feulgen reaction was performed with FEULGEN reaction for DNA kit (Bio-Optica Milano SpA, Milano, Italy) on $3-\mu \mathrm{M}$ frozen tissue sections derived from normal thyroid tissues, PTCs and ATCs sample tissues according to manufacturer's instructions.

\section{siRNA transfection}

TPC- 1 cells were seeded at $3 \times 10^{4}$ cells $/ \mathrm{cm}^{2}$, cultured for $18 \mathrm{~h}$, and transfected with siRNA against the MIF sequence, according to the siIMPORTER method (Upstate). After $72 \mathrm{~h}$, the cells were lysed and lysates were analyzed by western blotting. The siRNA controls were siRNA non-targeting (NT) and siRNA mock.

\section{MIF labeling and uptake experiments}

Recombinant human MIF protein (rMIF, Cell Guidance Systems, Cambridge, UK) was conjugated with the AlexaFlour 546/488 dye with the Microscale Protein Labeling Kit (A30006; Invitrogen). PTC cell lines were seeded at $12.5 \times 10^{4}$ cells $/ \mathrm{cm}^{2}$ and cultured for $18 \mathrm{~h}$. The medium was removed, and cells were washed twice with PBS to remove endogenous MIF. Alexa ${ }^{546}$ MIF or Alexa ${ }^{488} \mathrm{MIF}$ (pre-treated overnight with 4-IPP or untreated) was added directly to fresh culture medium to achieve a final concentration of $400 \mathrm{ng} / \mathrm{ml}$, and cells were cultured at $37^{\circ} \mathrm{C}$. After 0,30 , or $60 \mathrm{~min}$, cells were washed, fixed in $4 \%$ paraformaldehyde, and stained with anti-CD74 (ImmunoTools, Friesoythe, Deutschland), anti-CD44 (Cell Signaling Technology, Inc., Boston, MA, USA), or anti-CXCR4 (Abcam, Inc.). DAPI stain (Biostatus Limited) was used as a nuclear marker. Slides were imaged with immunofluorescence microscopy (Eclipse E1000; Nikon Instruments, Inc.).

\section{nLC-MS/MS analysis and isotope dilution mass spectrometry analysis}

TPC-1 cells were treated with 50 or $100 \mu \mathrm{M} 4$-IPP. After $24 \mathrm{~h}$, proteins secreted in the medium (secretome) by

Published by Bioscientifica Ltd. 
TPC-1 cells were collected and identified, as previously described (Caccia et al. 2011). Also, after 24 h, TPC-1 cells treated with $100 \mu \mathrm{M}$ 4-IPP were lysed; the lysate was analyzed by isotope dilution mass spectrometry, as previously described (Leoni et al. 2012).

\section{Antibodies}

The following antibodies were used for immunoblotting: anti-CD74, anti-MIF, anti-securin, anti-CXCR4, antiphospho-histone H3 (S10) (Abcam, Inc.), anti-cyclin B1 (Santa Cruz Biotechnologyies), anti-phospho-JNK (T183/Y182), anti-phospho-p38 ${ }^{\mathrm{MAPK}}$ (T180/Y182), anti-phospho-Akt (Ser 473), anti-Jab1, anti-cleavedPARP, anti-CD44, antiphospho-AMPK $\alpha$ (T172), anti-AMPK $\alpha$, anti-BCL2, antiphospho-mTOR (S2448), anti-mTOR, anti-phospho-p70 S6 kinase (T389), anti-p70 S6 kinase, anti-cyclin D1, antiERK1/2 (Cell Signaling Technology, Inc.), anti-phosphoERK1/2 (T183/Y185), anti- $\beta$-tubulin (Sigma-Aldrich).

\section{Statistical and pathway analysis}

Each experiment was performed at least three times. The statistical significance of the results was determined using Student's $t$-test. Data were considered significant when $P \leq 0.05$. Biological processes of significant proteins were analyzed with MetaCore (Thomson Reuters, Philadelphia, PA, USA). $P$ values reflect the probability that one or more proteins might be detected by chance. Statistical significance was ascertained with a false discovery rate (FDR) threshold of $<0.05$.

\section{Results}

\section{CD74 was up-regulated in a large subset of PTC cells}

CD74 and MIF expression patterns were investigated in 27 normal (including three cases of Hashimoto's thyroiditis), and 23 PTC tumor tissues with western blot analysis. PTC samples showed higher levels of CD74 than normal thyroid tissues (Fig. 1A). In addition, expression levels of the main MIF receptor, CD74, and a key MIF/CD74 downstream effector, cyclin-D1 were elevated in PTC samples compared to normal thyroid tissue (Fig. 1A). MIF and Jab1 protein levels were similar in PTC and normal tissues. Phospho-ERK (pERK) expression was variable among the different PTC samples. However, we noted that tumors with high levels of MIF and Jab1 exhibited low levels of pERK. Conversely, tumors with low Jab1 levels exhibited high levels of pERK (eg, PTC 3 and PTC 6 samples;
Fig. 1A). The most representative sections from normal (NT) and neoplastic thyroid tissues (PTC) (NT 3, NT 5, NT 7, PTC 6, PTC 9, PTC 11, and PTC 12) were immunostained for MIF and CD74 (Fig. 1B). Normal follicular cells exhibited strong perinuclear positivity for MIF, but endothelial cells and smooth muscle cells were MIF-negative. MIF was strongly expressed in all PTC samples tested and its staining pattern was mainly cytoplasmic (Fig. 1B).

CD74 immunostaining exhibited a weak cytoplasmic signal with a dot-like pattern in normal follicular epithelial cells. Scattered follicles showed stronger positivity. CD74 was also detected in endothelial cells, histiocytes, and lymphocytes when present. In some neoplastic tissues, CD74 staining was weak or moderate in $10-20 \%$ of tumor cells but, in other cases, staining was moderate in $>60 \%$ of tumor cells. The staining pattern was always cytoplasmic and membranous (Fig. 1B).

\section{Expression patterns of MIF and MIF-receptors in human PTC cell lines}

MIF is expressed in thyroid tumors and normal thyroid tissues. The main MIF receptor, CD74, was also detected in a fraction (70\%) of neoplastic tissues; CD74 was expressed in both epithelial and stromal compartments. This suggested that MIF and CD74 might play a functional role in conferring activities essential for tumor cell survival. Therefore, we assessed MIF protein levels in a panel of four PTC-derived cell lines, TPC-1, K1, NIM-1, and B-CPAP cells. In western blot analyses, we found that all four cell lines expressed high levels of MIF in both cell lysates and conditioned media (Fig. 2A). We also assessed the expression of MIF receptors, CD44, CXCR4, and CD74, and the intracellular binding partner, Jab1. Western blotting showed that high levels of CD44, CXCR4, and Jab1 were expressed in all four PTC-derived cell lines (Fig. 2A). However, although CD74 expression was strong in the TPC-1 cell line, it was nearly undetectable in the B-CPAP cell line, and it was not expressed in K1 or NIM-1 cells (Fig. 2A).

\section{Extracellular MIF taken up by endocytosis co-localized with CD74}

CD74 has been identified as the high-affinity binding protein for extracellular MIF. However, MIF-mediated signal transduction requires an interaction between CD74 and $\mathrm{CD} 44$, which involves the internalization of MIF via vesicle-mediated endocytosis (Kleemann et al. 2002). We investigated MIF-associated endosomal signaling mechanisms in TPC-1 and B-CPAP cell lines, which

Published by Bioscientifica Ltd. 
A

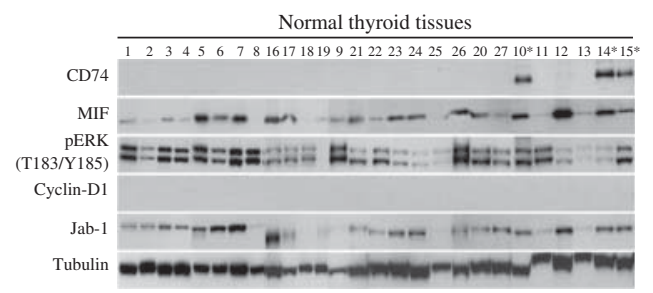

B
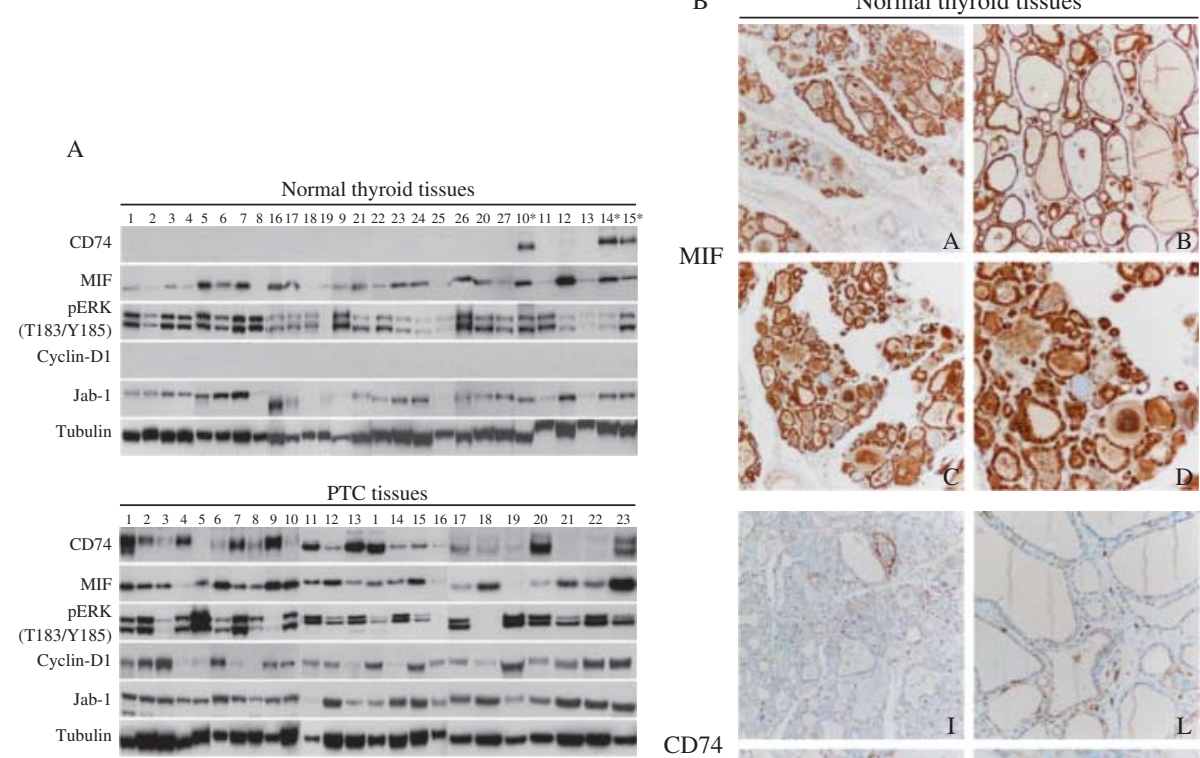

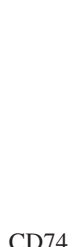
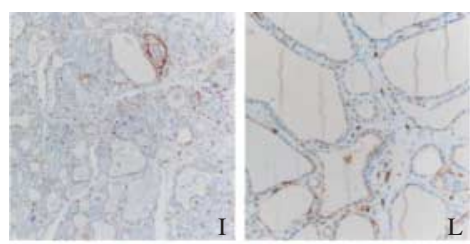

L
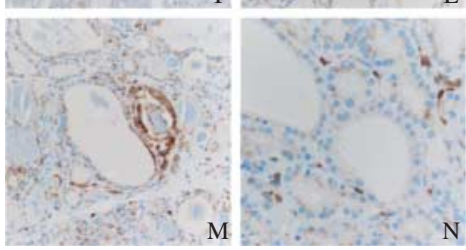
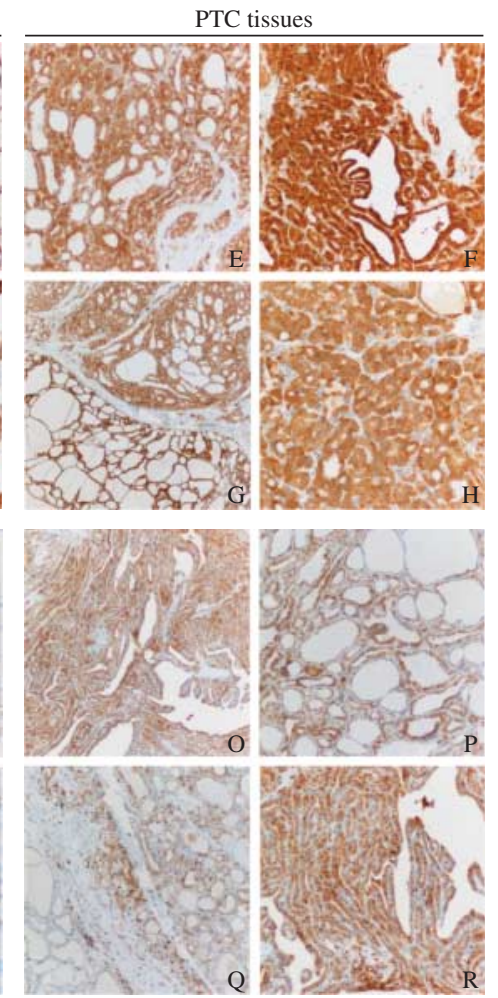

\section{Figure 1}

CD74 is up-regulated in a large subset of PTCs. Immunoblotting analysis of the principal proteins in the MIF/CD74 pathway. (A) PTC homogenates showed high CD74 and cyclin-D1 protein expression compared to normal thyroid tissues. MIF, Jab1 and pERK expression was similar in PTC and normal thyroid tissues. Homogenates were resolved on 4-12\% SDS-PAGE gels and immunoblotted with the indicated specific antibodies. Expression levels were normalized by comparing with $\beta$-tubulin. *The patient had Hashimoto thyroiditis. Western blot analysis were performed in triplicate.
(B) Immunohistochemical staining of normal (NT) and tumor (PTC) thyroid tissues with anti-MIF and anti-CD74 antibodies. Original magnifications are indicated in brackets, as follows: anti-MIF immunostaining: A, NT $5(10 \times)$; B, NT $7(10 \times)$; C, NT $3(10 \times)$; D, NT $5(20 \times)$; E, PTC $12(10 \times)$; F, PTC $11(20 \times)$; G, PTC $6(10 \times) ;$ H, PTC $9(20 \times)$. Anti-CD74 immunostaining: I, NT $5(10 \times)$; L (E), NT $7(10 \times)$; M, NT $5(20 \times)$; N, NT $5(40 \times)$; O, PTC $11(10 \times)$; P, PTC12 $(10 \times)$; Q, PTC $9(10 \times)$; R, PTC $11(20 \times)$.

in TPC-1 and B-CPAP cell lines, as previously described (Sanchez-Niño et al. 2013). The results showed a clear co-localization of CD74 and CD44 in TPC-1 cells, but only a modest co-localization in the B-CPAP cell line (Fig. 2D). Then, we incubated CD74-negative NIM- 1 and $\mathrm{K} 1$ cell lines with Alexa ${ }^{488} \mathrm{MIF}(400 \mathrm{ng} / \mathrm{ml})$ for 30 or $60 \mathrm{~min}$ at $37^{\circ} \mathrm{C}$. A negligible number of vesicle-like endocytotic structures were observed at both time points (Fig. 2E). Of note, rMIF appeared to localize in the nucleus or cytoplasm. In NIM-1 and $\mathrm{K} 1$ cells incubated with anti-CD44, Alexa ${ }^{488} \mathrm{MIF}$ co-localized weakly with the CD44 signal (Fig. 2F and G). In some immune processes, MIF acts as a non-cognate ligand of the CXCR4 chemokine receptor; because NIM-1 and $\mathrm{K} 1$ cell lines were CXCR4-positive, we also assessed whether Alexa ${ }^{488} \mathrm{MIF}$ co-localized with anti-CXCR4 antibodies. However, co-localization was very faint, which suggested that, in NIM-1 and K1 cell lines (Fig. 2F and G), MIF may signal through receptor-independent pathways. 
A
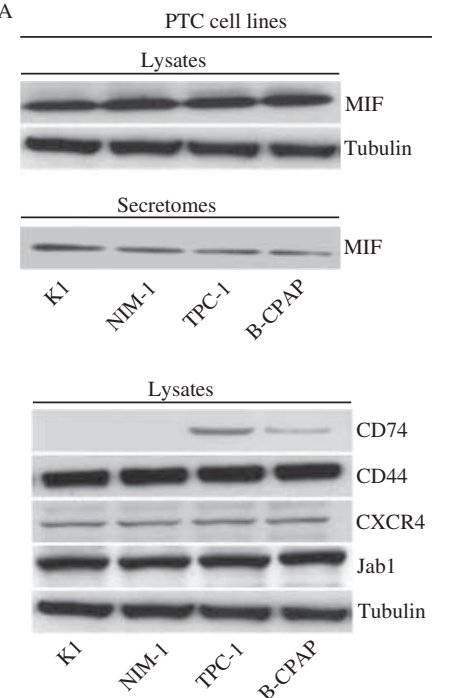

BMIF DAPI 0 min rMIF DAPI 30 min rMIF DAPI 60 min

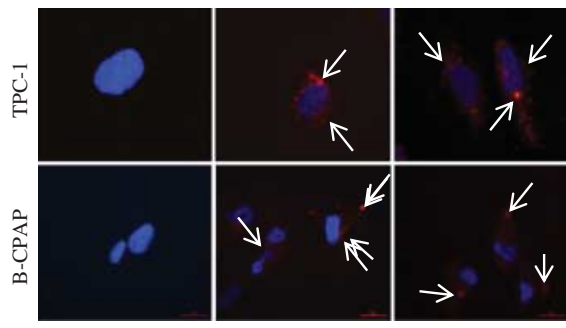

D

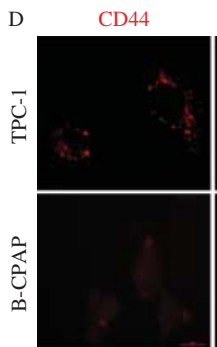

rMIF, DAPI

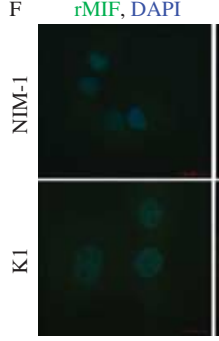

$\mathrm{CD} 74$

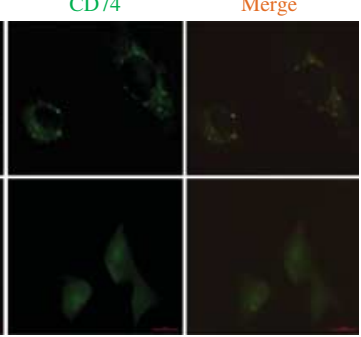

Merge

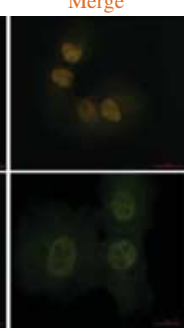

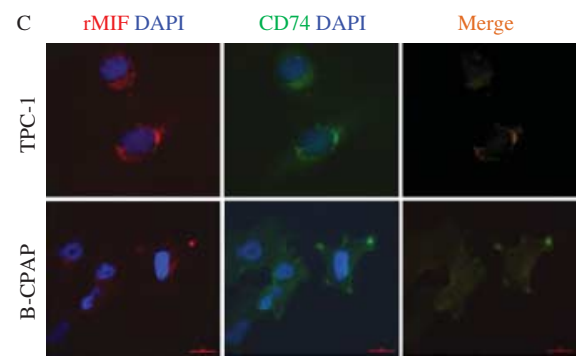

E rMIF DAPI 0 min rMIF DAPI 30 min rMIF DAPI 60 min
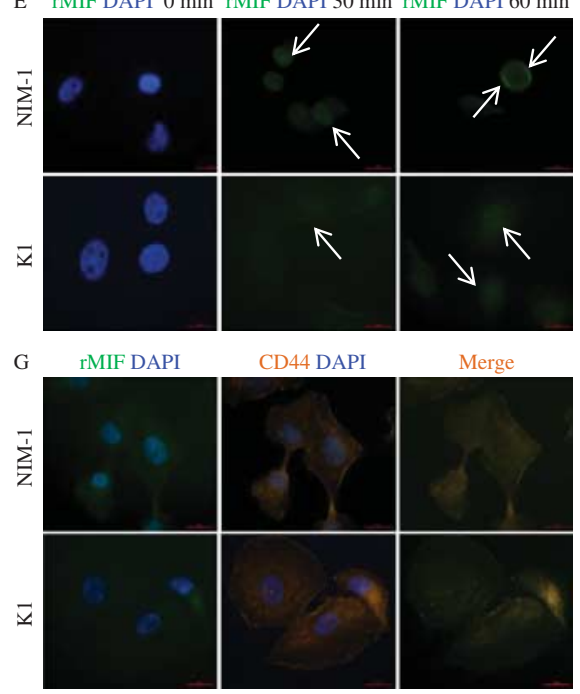

CD44 DAPI

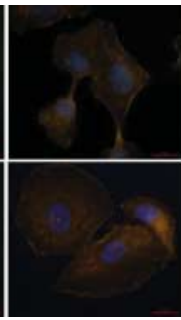

Merge

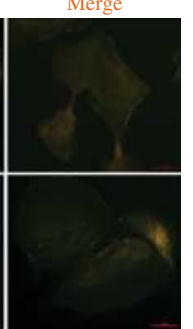

Figure 2

MIF is strongly expressed and released by human papillary thyroid cell lines. Endogenous MIF protein was measured in the lysates and conditioned media of human papillary thyroid carcinoma (PTC)-derived cell lines. In addition, endogenous CD74, CD44, CXCR4, and Jab1 protein levels were measured in PTC-derived cell line lysates. (A) Representative immunoblots of cell lysates and conditioned medium from the indicated cell lines. For all immunoblots, $\beta$-tubulin was used as loading control. Western blots analysis were performed in triplicate. (B) Extracellular MIF was endocytosed in vesicle-like structures via CD74. Cells were incubated with $400 \mathrm{ng} / \mathrm{ml}$ Alexa ${ }^{546} \mathrm{MIF}$ for 30 and $60 \mathrm{~min}$ at $37{ }^{\circ} \mathrm{C}$. Negligible staining at $0 \mathrm{~min}$ indicated that the signal was intracellular (not non-specific cell surface staining). At $30 \mathrm{~min}$, MIF was efficiently internalized in clearly detectable, vesicle-like structures (white arrows). (C) TPC-1 and B-CPAP cells treated with recombinant Alexa ${ }^{546} \mathrm{MIF}$ were immunostained for CD74. MIF and CD74 were strongly co-localized in TPC-1 cells and less strongly co-localized

These results were consistent with previous findings that MIF internalization was mediated by CD74/CD44 dependent and independent mechanisms.

\section{Changes in cell proliferation following MIF inhibition}

To investigate the molecular and cellular mechanisms associated with the targeting of MIF-dependent signaling, TPC-1, B-CPAP, NIM-1, and K1 cell lines were treated with the MIF inhibitor, 4-IPP at the following concentrations already reported in the literature: $10,25,50$ and $100 \mu \mathrm{M}$ in B-CPAP cells. (D) TPC-1 and B-CPAP cells stained with anti-CD74 and antiCD44 antibodies. CD74 and CD44 were strongly co-localized in TPC-1 cells, which suggested formation of a receptor complex. B-CPAP showed moderate CD74-CD44 co-localization. (E) Cells were incubated with $400 \mathrm{ng} / \mathrm{ml}$ Alexa ${ }^{488} \mathrm{MIF}$ for 30 and $60 \mathrm{~min}$ at $37{ }^{\circ} \mathrm{C}$. Fluorescent signals were negligible at $30 \mathrm{~min}$ and low at $60 \mathrm{~min}$. MIF was internalized less efficiently through a non-specific, non-receptor-mediated mechanism (white arrows). (F) NIM-1 and $\mathrm{K} 1$ cells treated with recombinant Alexa ${ }^{488} \mathrm{MIF}$ were immunostained to detect CXCR4 receptors. MIF and CXCR4 were weakly co-localized. (G) NIM-1 and K1 cells treated with recombinant Alexa ${ }^{488} \mathrm{MIF}$ were immunostained to detect CD44. MIF co-localization with CD44 was negligible. The figures show representative data of a representative experiment. All immunofluorescence experiments were performed in triplicate. Magnifications were $60 \times$ and $100 \times$. Scale bar $=50 \mu \mathrm{m}$.

(Winner et al. 2008). We confirmed the specific association between MIF and 4-IPP under our conditions with matrixassisted laser desorption/ionization time-of-flight mass spectrometry (MALDI-TOF-MS). After incubating rMIF and 4-IPP for $3 \mathrm{~h}$ at room temperature, we observed a mass shift of $\sim 282 \mathrm{Da}$, which corresponded to the molecular mass of 4-IPP. Thus, 4-IPP could effectively recognize its target (Supplementary Figure 1A, see section on supplementary data given at the end of this article). We evaluated the cellular and molecular effects of MIF inhibition by treating TPC-1, NIM-1, B-CPAP, and

Published by Bioscientifica Ltd 
K1 cells with various concentrations of 4 -IPP $(10,25,50$, and $100 \mu \mathrm{M})$. Twenty-four hours after treatment, the TPC-1 cells were rounded and exhibited highly refractive bodies, reminiscent of repair processes and/or cell death (Fig. 3A). Rhodamine-labeled phalloidin staining showed that 4-IPP induced a significant decrease in F-actincontaining stress fibers, and the actin filaments exhibited a dense, non-polar arrangement (Fig. 3B). B-CPAP, NIM-1, and $\mathrm{K} 1$ cells treated with 4-IPP showed no relevant changes in morphology.

A SRB analysis indicated that, after $72 \mathrm{~h}$ of $25 \mu \mathrm{M} 4$-IPP, TPC-1 cell proliferation decreased by up to $60 \%(P<0.001$; Fig. 3C, a). At 50 and $100 \mu \mathrm{M}$ 4-IPP, after $72 \mathrm{~h}$, TPC-1 proliferation was completely blocked and cell death occurred. B-CPAP cells showed similar effects with 4-IPP, but to lesser extent (Fig. 3C, b). In NIM-1 and K1 cell lines, low 4-IPP concentrations ( 10 and $25 \mu \mathrm{M}$ ) caused negligible effects; 4-IPP at $50 \mu \mathrm{M}$, after $72 \mathrm{~h}$, reduced cell proliferation by up to $25-30 \%$, but $100 \mu \mathrm{M} 4$-IPP caused a strong decrease in cell proliferation (Fig. 3C, c and d). Finally, we tested whether MIF and CD74 neutralization could impact proliferation in CD74-positive cell lines. Anti-MIF antibody, anti-CD74 antibody, or a control IgG1 was administrated to TPC- 1 cells at 2,4 , or $8 \mu \mathrm{g} / \mathrm{ml}$ for $0,24,48$, and $72 \mathrm{~h}$. The results clearly showed that MIF or CD74 immunodepletion strongly inhibited TPC-1 proliferation (Fig. 3D).

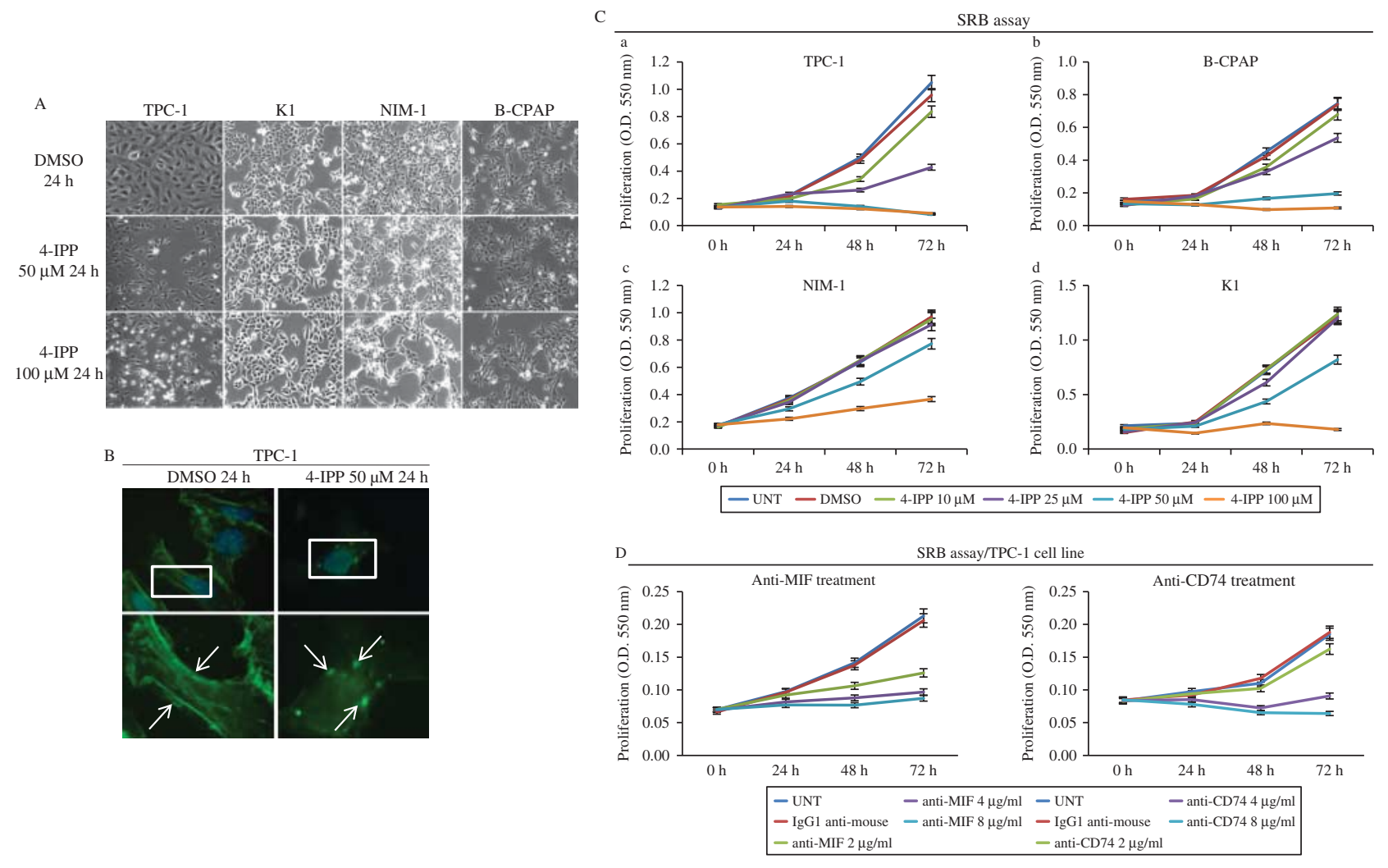

\section{Figure 3}

Effect of MIF inhibition on cell proliferation and growth. (A) Micrographs of TPC-1, B-CPAP, NIM-1, and K1 cells before and after drug treatments. 4-IPP treatment induced a marked morphological change in TPC-1 cells, resulting in a smaller, contracted appearance and decreased cell spreading. 4-IPP had no affect on the morphology of B-CPAP, NIM-1, and K1 cell lines.

(B) Immunofluorescence microscopy of TPC-1 cells before and after treatment with $50 \mu \mathrm{M}$ 4-IPP. Cells were stained with phalloidin to visualize actin. The figure shows data of a representative experiment. All immunofluorescence experiments were performed in triplicate. Magnifications: $60 \times$ and $100 \times$. Scale bars $=50 \mu \mathrm{m}$. (C) Proliferation curves of TPC-1, B-CPAP, NIM-1, and K1 cells treated with 4-IPP. After $72 \mathrm{~h}$ of $25 \mu \mathrm{M}$ 4-IPP, cell proliferation was significantly $(P<0.001)$ reduced in TPC-1 cells $(60 \%)$, (a) reduced in B-CPAP cells $(30 \%)$, and (b) unaffected in NIM-1 and (c) K1 cells (d). After $72 \mathrm{~h}$ at
50 and $100 \mu \mathrm{M}$ 4-IPP, (a) TPC-1 cells did not grow at all; (b) B-CPAP cell proliferation decreased by $80-90 \%(P<0.001)$; (c) NIM-1 cell proliferation was reduced by 20 and $60 \%$ respectively $(P<0.001)$; and (d) K1 cell proliferation was reduced by 40 and $90 \%$, respectively $(P<0.001)$. Representative growth curves from one experiment are shown. Each point represents the mean of eight independent replicates \pm s.D. (D) TPC- 1 cells were labeled with specific anti-MIF and anti-CD74 antibodies. After $72 \mathrm{~h}$, TPC-1 growth was reduced by $70 \%(2 \mu \mathrm{g} / \mathrm{ml}$ anti-MIF) to $90 \%(4$ and $8 \mu \mathrm{g} / \mathrm{ml}$ anti-MIF) $(P<0.001)$. After $72 \mathrm{~h}, 2 \mu \mathrm{g} / \mathrm{ml}$ anti-CD74 antibody reduced TPC-1 cell proliferation by $10-15 \%$, but at 4 and $8 \mu \mathrm{g} / \mathrm{ml}$, cell proliferation was reduced by 80 to $90 \%(P<0.001)$. Representative growth curves from one experiment are shown. Each point represents the mean of eight independent replicates \pm s.D. All proliferation assays were performed in triplicate.

Published by Bioscientifica Ltd. 


\section{AMPK is modulated in response to 4-IPP in CD74-positive TPC1 cell line}

To clarify MIF-induced signaling in tumor thyroid cells, we analyzed MIF signaling in CD74-positive and CD74-negative cell lines. Cells underwent siRNA-mediated MIF silencing and 4-IPP treatment. Silencing MIF in CD74-positive TPC-1 cells reduced ERK phosphorylation, the main downstream effect of the MIF/CD74 axis (Fig. 4B). Treatment with $100 \mu \mathrm{M}$ 4-IPP switched off ERK phosphorylation in TPC- 1 cells almost completely, though the level of protein expression was unmodified. Also, Akt and Jab1 phosphorylation was abrogated (Fig. 4A) and cyclinD1 expression levels were down-regulated (Fig. 4A). With $50 \mu \mathrm{M}$ 4-IPP, p38 and JNK phosphorylation levels were strongly increased in TPC-1 cells (Fig. 4A). In B-CPAP cells, 10,25 , and $50 \mu \mathrm{M} 4$-IPP slightly reduced ERK phosphorylation. However, at $100 \mu \mathrm{M}, 4$-IPP increased ERK and p38 phosphorylation and decreased cyclin-D1 expression (Fig. 4A). In CD74-negative K1 and NIM-1 cell lines, 4-IPP treatment did not significantly affect cyclin-D1 expression
(Fig. 4A). However, ERK-related p44 isoform expression and p38 phosphorylation were slightly increased (Fig. 4A). We next tested whether MIF/CD74 signaling activated AMPK in TPC-1 cells. MIF inhibition with 10, 25, 50, and $100 \mu \mathrm{M}$ 4-IPP strongly decreased AMPK phosphorylation. At $100 \mu \mathrm{M} 4$ 4-IPP, both mTOR phosphorylation and ribosomal protein $\mathrm{S} 6$ expression were reduced (Fig. 4C). However, 4-IPP treatment in B-CPAP, K1, and NIM-1 cell lines did not alter phosphorylated AMPK or mTOR expression (Fig. 4C). This result suggested that the MIF/CD74 signaling axis was involved in modulating the AMPK/mTOR pathway.

\section{Cell cycle effects of MIF inhibition}

To investigate the impact of MIF inhibition on cell cycle and cell death, we compared two PTC cell lines: TPC-1 (CD74-positive) and K1 (CD74-negative). TPC-1 and K1 cells were treated with different concentrations of 4-IPP (50 and $100 \mu \mathrm{M}$ ) for $0,12,24$, and $72 \mathrm{~h}$. FACS analysis of $\mathrm{K} 1$ cells stained with propidium iodide indicated that 4-IPP

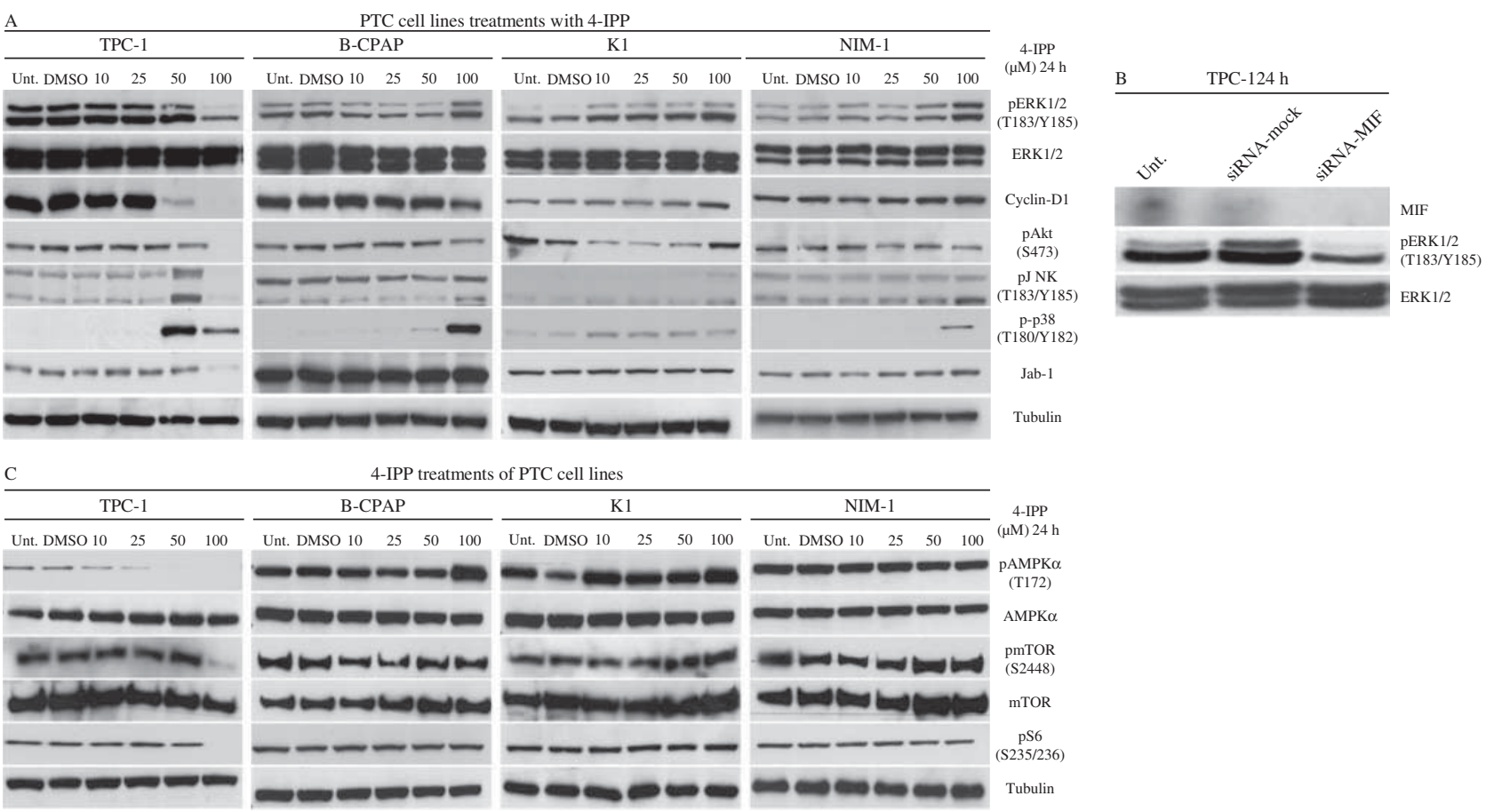

\section{Figure 4}

Time- and concentration-dependent molecular effects of MIF inhibition. (A) Immunoblots of the principal proteins involved in the CD74/MIF pathway. TPC-1, B-CPAP, NIM-1, and K1 cells were untreated or treated with $10,25,50$, and $100 \mu \mathrm{M} 4-$ IPP for $24 \mathrm{~h}$. Then, lysates were resolved by $4-12 \%$ SDS-PAGE and immunoblotted with specific antibodies as indicated. Expression levels were normalized to $\beta$-tubulin expression. (B) Western blot analysis of MIF and pERK $1 / 2$ expression in TPC- 1 cells treated with MIF
siRNA for $24 \mathrm{~h}$. Results were normalized with respect to total ERK protein $(P>0.005)$. (C) Immunoblots of the principal proteins involved in the AMP kinase (AMPK) pathway. TPC-1, B-CPAP, NIM-1, and $\mathrm{K} 1$ cells were untreated or treated with 10, 25, 50, $100 \mu \mathrm{M}$ 4-IPP for $24 \mathrm{~h}$. Cell lysates were resolved by $3-8 \%$ SDS-PAGE and immunoblotted with specific antibodies as indicated. Expression levels were normalized to $\beta$-tubulin expression. Western blot analysis were performed in triplicate.

Published by Bioscientifica Ltd. 
A
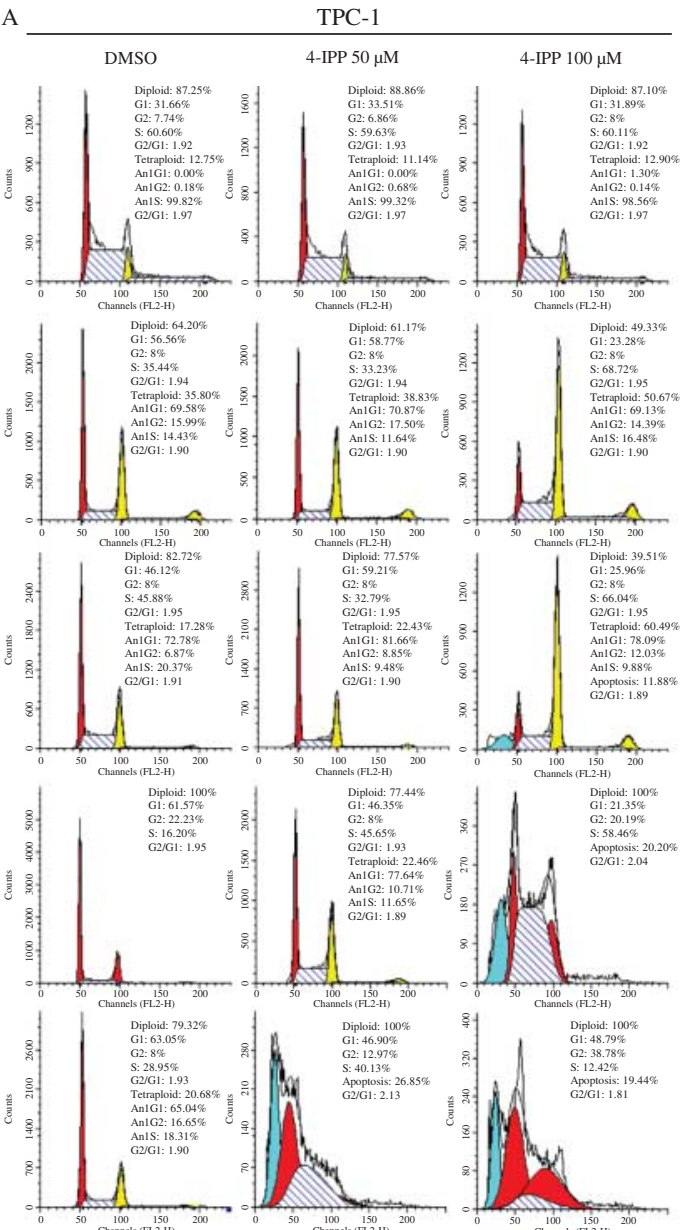

Figure 5

Cell cycle effects of MIF inhibition. (A) Cell cycle analysis of TPC-1 and K1 cells exposed to 4-IPP. Representative flow cytometric profile of cell cycles in TPC-1 and K1 cells, analyzed with propidium iodide staining. Analysis was performed with the CellQuest program (Becton Dickinson). Treatments and the percentage of cells in the difference phase of cell cycle are
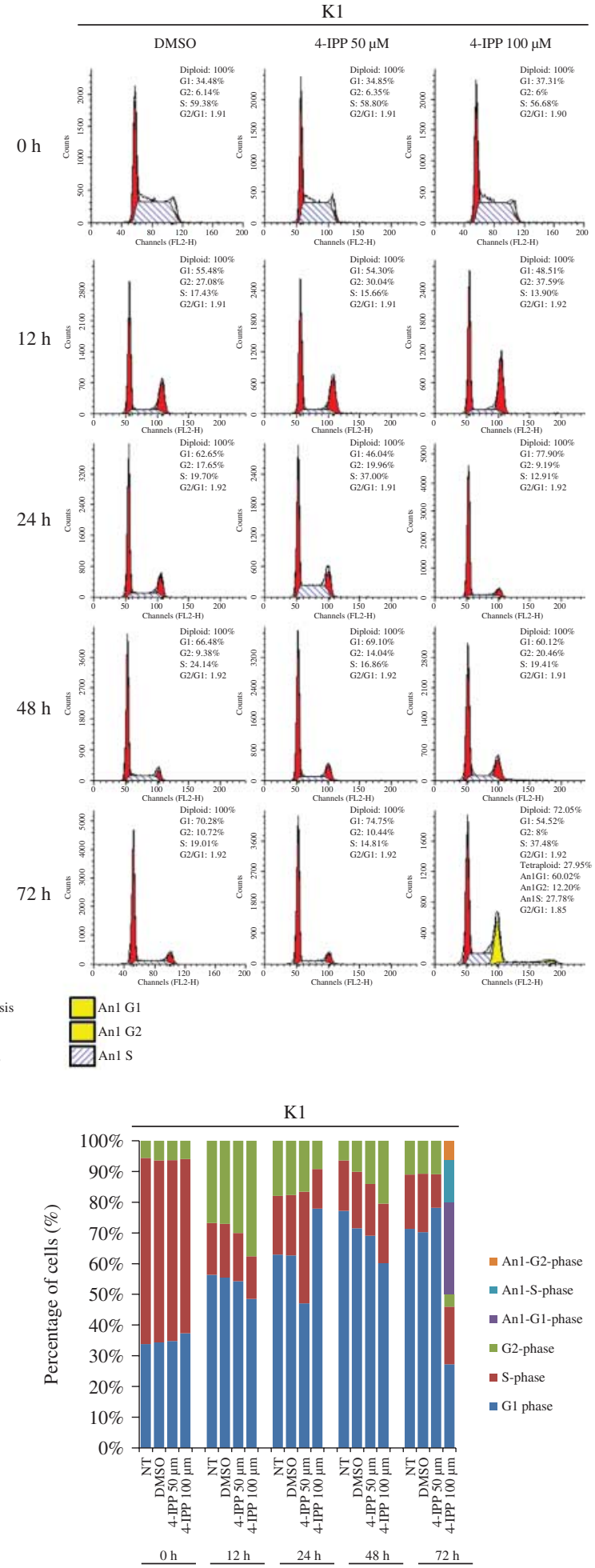

indicated. The figure show data from a representative experiment and all experiments were performed in triplicate. (B) Bar-graph represents the relative percentage of TPC-1 and K1 cells in various cell cycle phases over time in the presence of 50 or $100 \mu \mathrm{M} 4$-IPP. The values represent the average of three independent experiments.

Published by Bioscientifica Ltd. 
only slightly impacted the cell cycle (Fig. 5A). Cell cycle analysis of untreated TPC- 1 cells at $0,12,24$, and $72 \mathrm{~h}$ of culture revealed a mixture of diploid and tetraploid cells. Tetraploidization was present in $10-35 \%$ of the cells. However, at $48 \mathrm{~h}$, they were completely depolyploidized and had re-entered the mitotic cycle. When TPC- 1 cells were treated with $50 \mu \mathrm{M}$ 4-IPP for $48 \mathrm{~h}$, a fraction of cells (27.44\%) maintained tetraploidy. However, after $72 \mathrm{~h}, \mathrm{a}$ similar fraction of cells (26.85\%) became apoptotic (Fig. 5A and B). Treatment of TPC-1 cells with $100 \mu \mathrm{M} 4$-IPP for $24 \mathrm{~h}$ caused $11.88 \%$ apoptosis, an increase in S-phase (66.04\%) diploid cells, and an accumulation of cells with $4 \mathrm{~N}$ DNA content (60.49\%). We tentatively attributed the latter finding to arrest in the G2/M transition (Fig. 5A and B). Longer incubations led to a large increase in the number of arrested cells; $20.20 \%$ were apoptotic, and the remaining cells had 2N DNA contents. After $48 \mathrm{~h}$, the TPC1 cells undergoing apoptosis increased, and cells accumulated in the G1 phase (46.90\%) and the S-phase (40.13\%); after
$72 \mathrm{~h}$, cells accumulated in the G2/M-phase (38.78\%) and the G1-phase (48.79\%). Microscopic analysis of treated cells indicated a high number of cells with marked nuclear abnormalities, including multinucleation in all cell lines indicating abnormal mitosis with failed cytokinesis.

Taken together, these data clearly indicated that 4-IPP induced multinucleated cells and some of the nuclei show morphologic features of apoptotic cell death consistent with mitotic catastrophe in a dose- and time-dependent manner. To support the notion that MIF inhibition could induce these effects in TPC-1 cells, we compared the nuclei and microtubule cytoskeletons to those of $\mathrm{K} 1$ cells with immunofluorescence. TPC- 1 and $\mathrm{K} 1$ cells were treated with 50 and $100 \mu \mathrm{M} 4$-IPP for 24,48 , and $72 \mathrm{~h}$. Before treatment, both cell lines showed typical radial, diffuse microtubules (green $\beta$-tubulin, Fig. 6A) and normally shaped nuclei (blue; Fig. 6A).

The 4-IPP treatment did not change the morphology, microtubule organization, or nuclei in $\mathrm{K} 1$ cells.
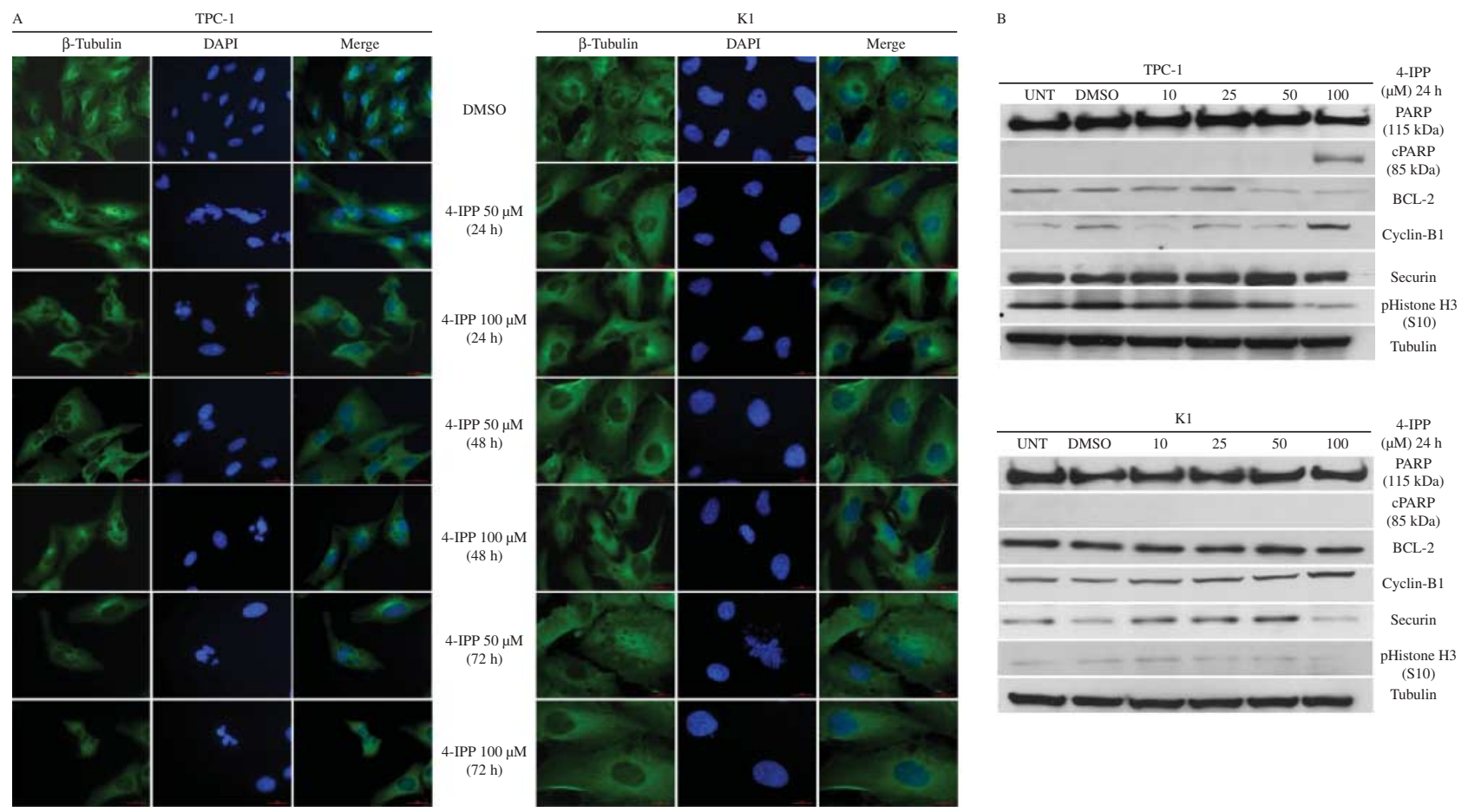

\section{Figure 6}

MIF inhibition disrupts microtubule networks in CD74-positive cell line. (A) Coverslips with TPC-1 $\left(\mathrm{CD} 74^{+}\right)$and $\mathrm{K} 1\left(\mathrm{CD} 74^{-}\right)$cells were incubated with 50 or $100 \mu \mathrm{M} 4$-IPP or with DMSO (vehicle) for 24,48 , and $72 \mathrm{~h}$. Then cells were fixed and stained with anti- $\beta$-tubulin antibody (green) to visualize microtubules and with DAPI (blue) to visualize cell nuclei. Fluorescence micrographs show untreated TPC-1 cells with typical radial microtubule arrays. After 24,48 , and $72 \mathrm{~h}$ of 4-IPP treatment, microtubule organization was disrupted in TPC-1 cells. The formation of giant, multinucleated cells was characteristic of mitotic catastrophe. In contrast,
K1 cells treated with 4-IPP showed typical radial microtubule arrays and normal nuclei organization. The figures show data of a representative experiment. All immunofluorescence experiments were performed in triplicate. Magnification: $60 \times$. Scale bar: $50 \mu \mathrm{M}$. (B) Western blot analysis of cleaved PARP, BCL-2, cyclin-B1, securin and phospho-histone-H3 (S10) in TPC-1 and K1 cell lines treated with 10, 25, 50, or $100 \mu \mathrm{M} 4$-IPP for $24 \mathrm{~h}$. Expression levels were normalized to $\beta$-tubulin expression. Western blot analysis were performed in triplicate.
(C) 2015 Society for Endocrinology Printed in Great Britain
Published by Bioscientifica Ltd 


\begin{tabular}{|c|c|c|c|c|c|}
\hline & & & Metabolic network & $P$-value & FDR \\
\hline $\begin{array}{l}\text { Process } \\
\text { network }\end{array}$ & $P$-value & FDR & Carbohydrate & & \\
\hline $\begin{array}{l}\text { Proteolysis } \\
\text { ECM } \\
\text { remodeling }\end{array}$ & $1.597 \times 10^{-5}$ & $1.277 \times 10^{-4}$ & $\begin{array}{l}\text { Glycolysis, } \\
\text { gluconeogenesis } \\
\text { and glucose } \\
\text { transport }\end{array}$ & $4.908 \times 10^{-5}$ & $1.031 \times 10^{-4}$ \\
\hline
\end{tabular}

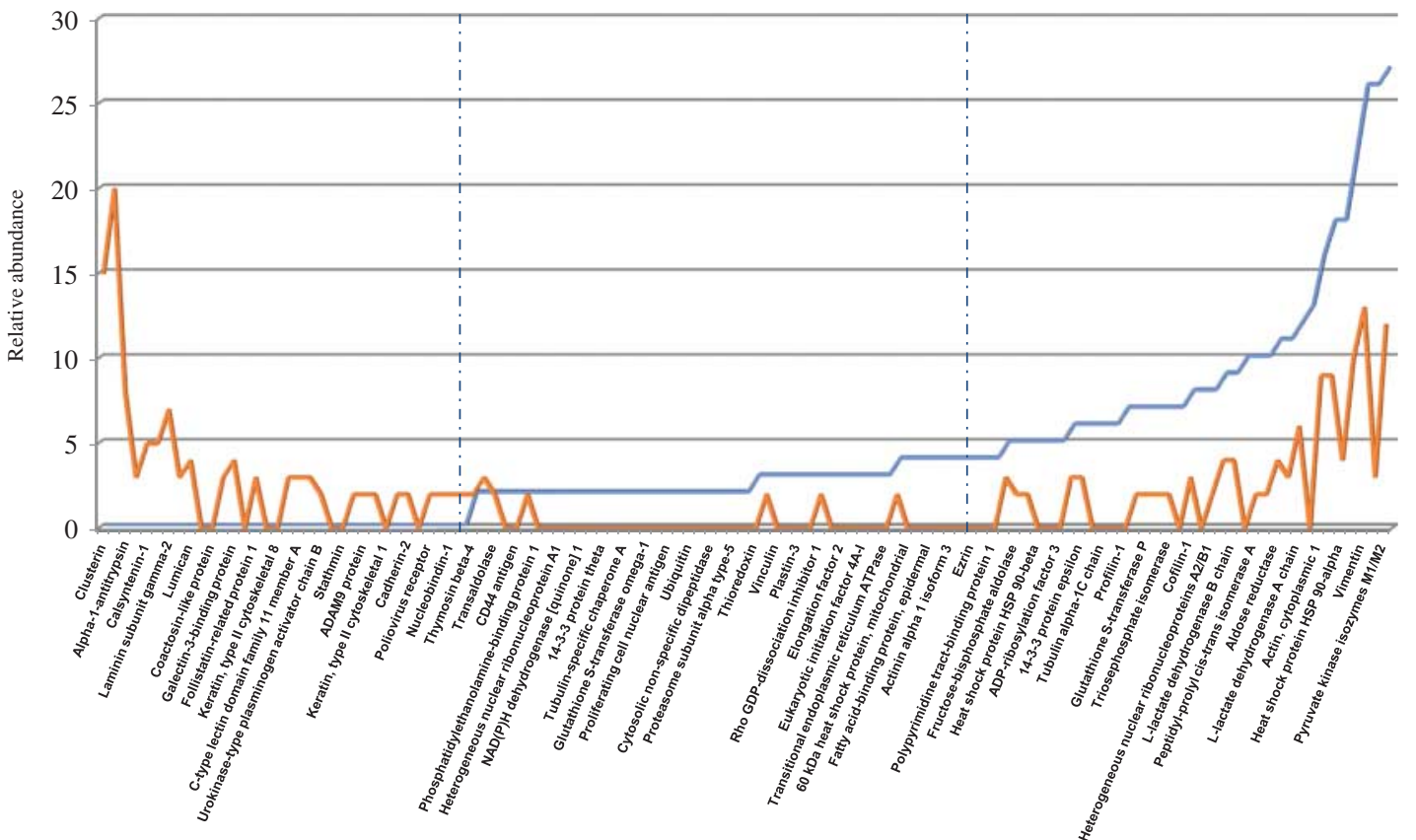

B

\begin{tabular}{|c|c|c|c|c|c|c|c|c|c|}
\hline & Lactate & Pyruvate & Citrate & Succinate & Fumarate & Malate & Cholesterol & Lathosterol & Lanosterol $\frac{\mathrm{ng}}{\mathrm{mg}_{\text {proteins }}}$ \\
\hline $\mathbf{U N T}$ & 3442 & 138 & 839 & 487 & 161 & 83 & 18400 & 142 & 35 \\
\hline $\begin{array}{c}\text { 4-IPP 100 } \\
\mu \mathrm{M}\end{array}$ & 5512 & 520 & 320 & 571 & 86 & 135 & 15531 & 76 & 26 \\
\hline
\end{tabular}

\begin{tabular}{|c|c|c|c|c|c|c|c|c|}
\hline & C16:1 & $\mathrm{C} 16: 1 \omega 7$ & $\mathrm{C} 16$ & C18:2 & C18:1 & 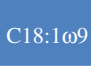 & $\mathrm{C} 18$ & $\frac{\mathrm{ng}}{\mathrm{mg}_{\text {proteins }}}$ \\
\hline UNT & 2192 & 435 & 35778 & 5637 & 53385 & 12081 & 22550 & \\
\hline $\begin{array}{c}\text { 4-IPP } 100 \\
\mu \mathrm{M}\end{array}$ & 2992 & 268 & 29599 & 5473 & 55289 & 8579 & 24506 & \\
\hline
\end{tabular}

Figure 7

MIF inhibition produces proteomic and metabolic changes. (A) Proteins in conditioned medium were assessed for function before and after 4-IPP treatment. The $P$ value from the hypergeometric test, generated by Metacore, represents the enrichment of certain proteins; those included in the processing network, 'Proteolysis_ECM remodeling', for untreated TPC-1 cells (orange line), or those included in the metabolic network, 'Carbohydrate metabolism_Glycolysis, Gluconeogenesis and glucose

In contrast, 50 and $100 \mu \mathrm{M} 4$-IPP disrupted the microtubule networks in TPC- 1 cells after $24 \mathrm{~h}$. Furthermore, these cells exhibited micro- and multinucleation, similar to previous descriptions of mitotic catastrophe transport', for 4-IPP treated TPC-1 cells (blue line). The FDR value is also reported (B). The table show the values of the metabolites analyzed after TPC-1 treatment with 4-IPP at $100 \mu \mathrm{M}$. The results were expressed as $\mathrm{ng} / \mathrm{mg}_{\text {proteins }}$ and were normalized to the value of total proteins present in each sample. Data and values represent the average of three independent experiments.

(blue-stained nuclei, Fig. 6A). The same results were obtained with $100 \mu \mathrm{M}$ 4-IPP after 48 and $72 \mathrm{~h}$. TPC-1 cells treated with $100 \mu \mathrm{M}$ 4-IPP accumulated cyclin-B1 (Fig. 6B), and they maintained securin expression.

Published by Bioscientifica Ltd. 
A

Scatter plots of densitometry results
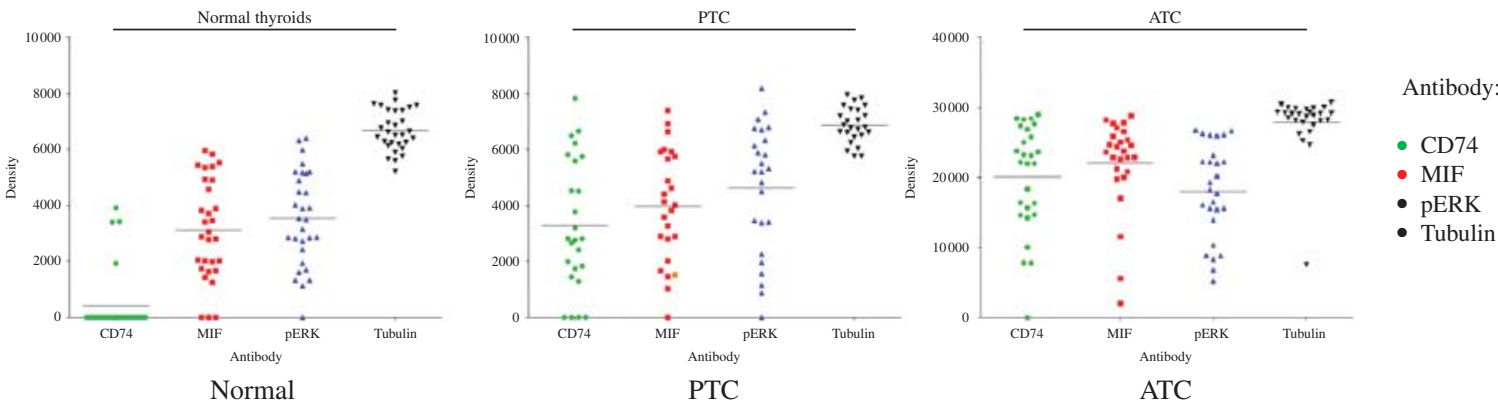

B
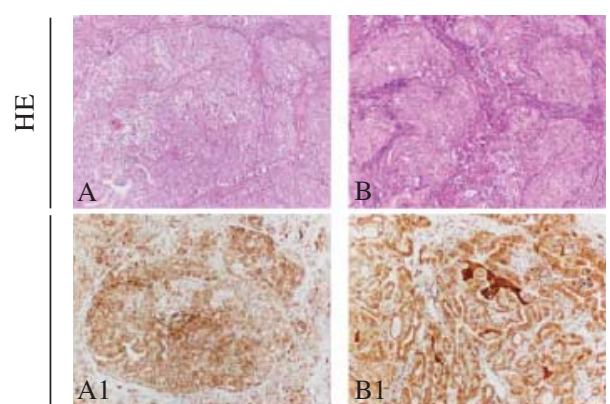

过

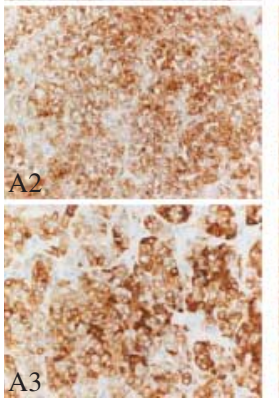

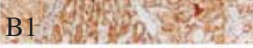

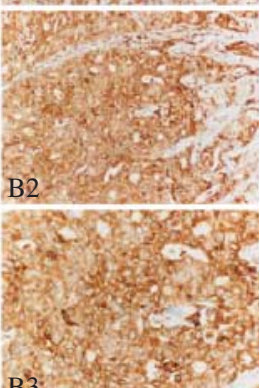

C Feulgen Staining

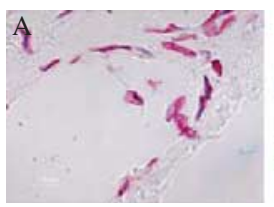

Normal

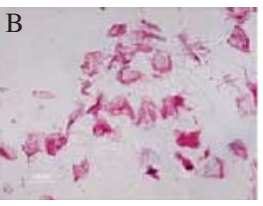

PTC

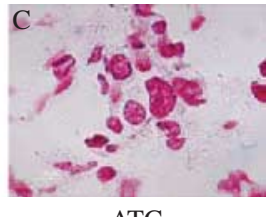

ATC

$$
\text { D SRB assay (HTC-C3 cell line) }
$$

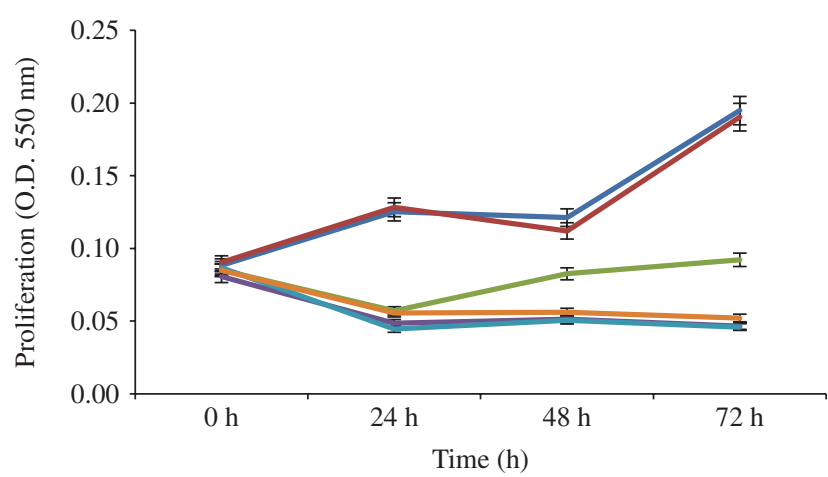

E

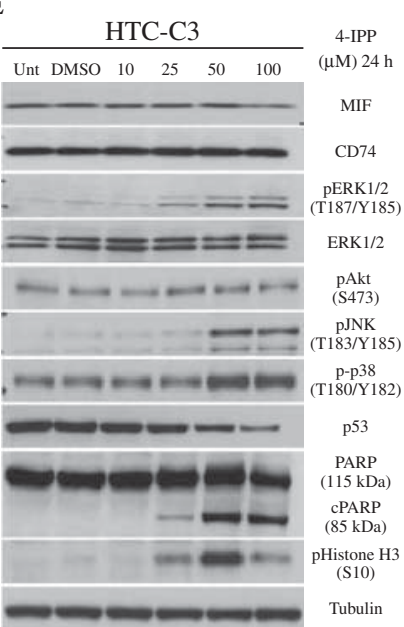

F \begin{tabular}{|lll}
\hline UNT & - DMSO & - 4-IPP $10 \mu \mathrm{M}$ \\
- 4-IPP $25 \mu \mathrm{M}$ & - 4-IPP $50 \mu \mathrm{M}$ & - 4-IPP $100 \mu \mathrm{M}$ \\
\hline
\end{tabular}

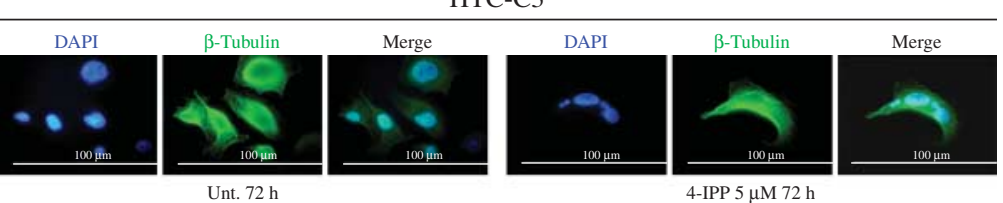

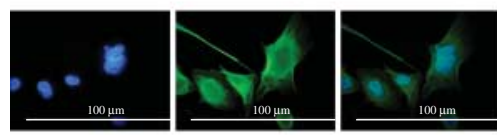
DMSO $72 \mathrm{~h}$
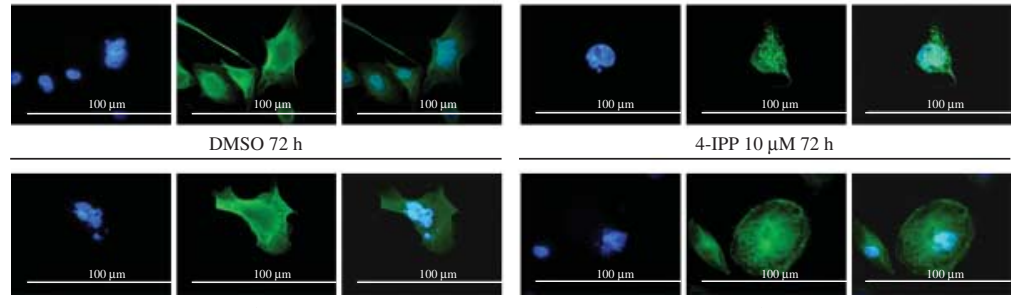

4-IPP $10 \mu \mathrm{M} 72 \mathrm{~h}$

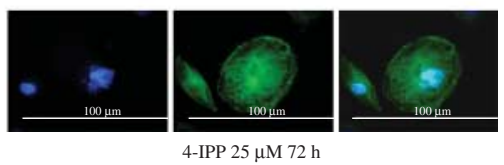


These findings supported the notion that 4-IPP suppressed a cell-cycle checkpoint and caused a deficit in chromosome separation. In contrast, no changes were observed in cyclin-B1 expression in K1 cells (Fig. 6B). The 4-IPP (at $100 \mu \mathrm{M}$ after $24 \mathrm{~h}$ ) treatment also caused a cleavage in PARP and reduced the expression of the anti-apoptotic protein, BCL-2 in TPC-1 cells; these factors led to favorable conditions for apoptosis (Fig. 6B). In contrast, 4-IPP did not activate PARP or reduce BCL-2 expression in K1 cells. Taken together, our results suggested that inhibiting the MIF/CD74 axis led to TPC-1 cell death, probably through a mitotic catastrophe. As shown in Fig. 5A and B, and consistent with previous cell proliferation studies (Fig. 3C), we found that $100 \mu \mathrm{M} 4$-IPP induced a population of multinucleate cells at $72 \mathrm{~h}$ in $\mathrm{K} 1$ cells. Thus, 4-IPP apparently led to G2/M arrest and multinucleation.

These results showed that 4-IPP treatment in CD74negative cells resulted in a dose- and a time-dependent G2/M arrest and multinucleation.

\section{MIF inhibition produces proteomic and metabolic changes}

Proteins secreted in the culture medium (secretome) represent activities, properties, and functional activities of tumor cells (Caccia et al. 2011). We analyzed the proteins secreted by TPC-1 cells in the presence or absence of MIF inhibition to identify key mediators of the 4-IPP effects produced in TPC-1 cells. We profiled the secretome of TPC- 1 cells subjected to $24 \mathrm{~h}$ of 50 and $100 \mu \mathrm{M} 4$-IPP with LC-MS/MS and label-free quantitative proteomics approaches. As expected, many released proteins were mediators of critical cellular functions that were modulated by MIF (Fig. 7A). Specifically, we found that MIF inhibition was associated with the modified release of proteins involved in glycolysis/gluconeogenesis (Fig. 7A). We also performed isotope-dilution gas chromatography mass spectrometry (GC-MS) analysis (Leoni et al. 2012) of cellular lysates after $24 \mathrm{~h}$ 4-IPP treatment. We found that lactate, pyruvate, and malate were elevated and citrate and fumarate were reduced (Fig. 7B). We hypothesized that 4-IPP caused a partial inefficiency in the mitochondrial tricarboxylic acid cycle (suggested by reduced citrate and fumarate, Fig. 7B), possibly due to a reduction in oxidative phosphorylation efficiency, which reduced ATP synthesis. The conversion of pyruvate into lactate can regenerate NAD and increase the activity of malic dehydrogenase (i.e., we found elevations in malate). With impaired mitochondrial function, glycolysis may be increased to maintain adequate ATP production, when ATP consumption is reduced. The 4-IPP treated cells also showed reductions in cholesterol, fatty acids, and cholesterol synthesis (Fig. 7B). These findings were consistent with the hypothesis that 4-IPP suppressed mitochondrial activity and activated glycolysis and lactate production. Thus, 4-IPP may cause changes in cellular ATP production.

\section{ATC sensitivity to 4-IPP inhibitor}

To further evaluate the relevance of the MIF/CD74 signaling axis in undifferentiated/anaplastic carcinoma presenting marked nuclear pleomorphism, we determined the expression of MIF/CD74 signaling components

\section{Figure 8}

Anaplastic thyroid carcinoma sensitivity to 4-IPP inhibitor. (A) Scatter plots showing densitometric scan values of western blot band of normal thyroid, PTC and ATC samples using antibodies against CD74, MIF, pERK and $\beta$-tubulin. The values, normalized to $\beta$-tubulin and expressed as fold changes, refer to 27 normal thyroid tissues, 23 PTC and 27 ATC tissues. (B) Hematoxylin eosin and immunohistochemical staining of two representative ATC tissues ( $A$ and $B$ ) with anti-CD74 antibody. Original magnifications are indicated in brackets, as follows: hematoxylin eosin staining: A, ATC sample $1(10 \times)$; $B$, ATC sample $2(10 \times)$. Anti-CD74 immunostaining: A1, ATC sample $1(10 \times)$; B1, ATC sample $2(10 \times)$; $A 2$, ATC tissue one $(20 \times)$; B2, ATC tissue two $(20 \times)$; A3, ATC tissue one $(40 \times)$; $B 3$, ATC tissue two $(40 \times)$. (C) Feulgen staining of normal thyroid tissue $(A)$, PTC tissue (B) and ATC tissue (C). The figure shows the most representative tissue section for each groups of tissue samples (normal tissue, PTC and ATC). Magnification: $100 \times$ oil. Scale bar: $100 \mu \mathrm{M}$. (D) Proliferation curves of HTC-C3 cells treated with 4-IPP. After $24 \mathrm{~h}$ of $10,25,50$, and $100 \mu \mathrm{M} 4-I P P$, cell proliferation was significantly $(P<0.001)$ reduced in HTC-C 3 cells $(70-80 \%)$. After $72 \mathrm{~h}$ at 25,50 , and $100 \mu \mathrm{M}$ HTC-C3 cells did not grow at all. At $10 \mu \mathrm{M}$ of 4-IPP cell proliferation was dramatically reduced in HTC-C3 cell line $(70 \% ; P<0.001)$. Representative growth curves from one experiment are shown. SRB assay was performed in triplicate. Each point represents the mean of eight independent replicates \pm s.D. (E) Western blot analysis of CD74, MIF, pERK, ERK1/2, pAkt, pJNK, phosphor-p38, p53, cleaved PARP and phosphor-histone $\mathrm{H} 3$ in HTC-C3 cell extracts. HTC-C3 cells were untreated or treated with 10, 25, 50, and $100 \mu \mathrm{M}$ 4-IPP for $24 \mathrm{~h}$; then, lysates were resolved by 4-12\% SDS-PAGE and immunoblotted with specific antibodies as indicated. Expression levels were normalized to $\beta$-tubulin expression. Western blot analysis were performed in triplicate. (F) Coverslips with HTC-C3 (CD74-positive) cells were incubated with 2,5, 5, 10 or $25 \mu \mathrm{M}$ 4-IPP or with DMSO (vehicle) for $72 \mathrm{~h}$. Then cells were fixed and stained with $\beta$-tubulin antibody (green) to visualize microtubules and with DAPI (blue) to visualize cell nuclei. Fluorescence micrographs show untreated HTC-C3 cells with typical radial microtubule arrays. In contrast, treated cells frequently developed multiple nuclei, including micronuclei. Microtubule organization was disrupted and, as well, cells were also much larger than untreated HTC-C3 cells. These features were characteristic of mitotic catastrophe. The figures show representative data from a representative experiment. All immunofluorescence experiments were performed in triplicate. Magnification: $60 \times$. Scale bar: $100 \mu \mathrm{M}$. 
in 27 ATC tissues by western blot and of CD74 in representative sections of 27 patient samples by IHC staining. Results showed that in all tumors, the malignant cells strongly expressed CD74 (Fig. 8B). Some tumors also showed positivity in the stromal components (Fig. 8B). Quantification of the western blot data for CD74, MIF, and pERK proteins demonstrated a strong increase in the expression levels of CD74 protein in the ATC samples when compared with PTC and normal thyroid samples (Fig. 8A). Nuclear pleomorphism in ATC samples was ascertained by performing the Feulgen reaction (Fig. 8C).

We assessed whether 4-IPP could inhibit the MIF/CD74 signaling axis by determining its effects on cell proliferation and the expression of targets in a HTC-C3 cell line positive for both CD74 and MIF. Sensitivity to 4-IPP was observed and the cytotoxic efficacy of 4-IPP in treated cells was assessed at different concentrations and times. As illustrated in Fig. 8D, the HTC-C3 cells were highly sensitive in the range of $\sim 10-100 \mu \mathrm{M}$ of inhibitor, demonstrating that 4-IPP could reduce the proliferation rate of this anaplastic cell line. To better understand the molecular mechanisms of cell death induced through 4-IPP treatment, we conducted western blot analysis of treated HTC-C3 cells. As shown in Fig. 8E, treatment led to an increase in JNK and phospho-p38 activity in a dosedependent manner.

The 4-IPP-treated cells were also much larger than untreated cells (Fig. 8F). Most treated cells developed multiple nuclei, and in some cases, we observed the formation of micronuclei, including misfolding microtubules. To evaluate whether 4-IPP induces cell cycle arrest at mitosis, we stained cells with anti-phospho-histone $\mathrm{H} 3$ (serine 10), a mitotic marker, and DAPI, a DNA-specific dye (Supplementary Figure 1B). In response to 4-IPP treatment $(2.5-25 \mu \mathrm{M})$, cells showed a time- and concentrationdependent increase in positivity. Western blot analysis of protein expression levels of phospho-histone H3 showed an increased response to the 4-IPP treatment (Fig. 8E). Treated cells displayed a significant increase in cleaved PARP (CPARP) whereas total $\beta$-tubulin levels remained the same. Overall, the results suggested that 4-IPP could lead to a cell cycle arrest in the $\mathrm{G} 2 / \mathrm{M}$ phase, triggering arrestmediated apoptotic cell death.

\section{Discussion}

This study was the first to show that MIF was abundantly expressed in both normal and cancerous thyroid tissues, though with different subcellular localizations. In 70\% of PTC and $100 \%$ of ATC cases, neoplastic tissues showed expression of CD74 in cells other than those in the lymphocyte population.

To investigate the functional significance of MIF/CD74 signaling, we inhibited MIF activity with 4-IPP in CD74-positive and CD74-negative cell lines. Our results indicated that i) CD74 was essential for obtaining significant cell proliferation inhibition and inducing cell death; ii) untreated TPC-1 cells showed an AMPK and ERK activation that was sensitive to 4-IPP whereas JNK phosphorylation was barely detected and spontaneous endoreduplicative and apoptotic processes coexisted; iii) at $24 \mathrm{~h}$ of culture of TPC-1 cells, a large fraction of polyploid cells had escaped death and initiated a de-polyploidization process producing viable descendants, probably through reduction division or alternative mechanisms; iv) 4-IPP treatment dose-dependently inhibited proliferation by blocking the $\mathrm{G} 2 / \mathrm{M}$ transition and induced TPC-1 cells to exhibit the morphological features of mitotic cell death; v) concomitantly with treatments, we observed a strong reduction in AKT, ERK, and AMPK phosphorylation, increased Jab1, and the appearance of a peak of JNK and p38 phosphorylation; and vi) 4-IPP effects were recapitulated in the anaplastic (CD74-positive) thyroid HTC-C3 cell line.

Treatment with 4-IPP produced consequences similar to those seen with isothiocyanates, a group of plant-based chemicals present in cruciferous vegetables that are part of the human diet. These compounds are thought to prevent cancer and principally target MIF in intact cells (Higdon et al. 2007). As noted, similar effects were also obtained using an Ebselen compound (Supplementary Figure $1 \mathrm{E}$ and $\mathrm{F}$ ).

Results with the 4-IPP treatments indicate that the MIF/CD74 axis supports the proliferative and metabolic pathways. These functions have been previously reported in other studies. MIF stimulates heart muscle glucose uptake, and the autocrine/paracrine effects of endogenous cardiac MIF contribute to AMPK activation and glucose uptake during ischemia (Qi et al. 2009). Thus, AMPK is considered a type of cardioprotective stress kinase (Russell et al. 2004), and the action of MIF modulation of AMPK is beneficial during ischemia.

We found that a failure in MIF/CD74 signaling reduced AMPK function. In parallel, cell cycle arrest and mitotic cell death were observed. Our metabolomic analysis produced results that were consistent with the hypothesis that 4-IPP may cause reduced oxidative phosphorylation efficiency, decreasing ATP synthesis. We believe that in the TPC- 1 cell line, the MIF/CD74

Published by Bioscientifica Ltd. 
axis may produce a higher energy state of the cell (glucose uptake) by accelerating either ATP production or consumption. AMPK could also contribute to mitochondrial function, stimulating mitochondrial biogenesis via phosphorylation of the PGC1 co-activator and regulating expression of mitochondrial genes (Li et al. 2011).

Vazquez-Martin et al. reported a physical interplay between active AMPK with mitotic regulators in the centrosome and midbody. Thanks to these relationships, AMPK coordinates sensing of energy resources and the fundamental biological process of genome division during mitosis and cytokinesis. The same authors analyzed the phenotypes that resulted from pharmacologically induced overactivation of AMPK and observed a dramatic reorganization compatible with multinucleation, with the proportion of polyploid cells reaching $>30 \%$ of the total population (Vazquez-Martin et al. 2009). We think that MIF/CD74 axis might reproduce the effects of a pharmacologically induced overactivation of AMPK, which is likely responsible for supporting an energetic infrastructure underlying an aberrant mitotic/cytokinetic machinery.

Suppression of MIF/CD74 signaling not only blocks this bioenergetic resource but also increases oxidative stress, activating JNK and the stress response and producing cell death. Of interest, Yun et al. (2009) have shown how glucose deprivation activates JNK and apoptotic signals in DU145 cells. Reactive oxygen species production may be crucial in linking glucose deprivation induced by the AMPK and JNK signaling pathways. In agreement with previously reported results (Bech-Otschir et al. 2002), our findings show that a lack of MIF provoked recovery of Jab1, which could contribute to the activation of JNK.

The p53 expression in the TPC- 1 cell line did not change with 4-IPP treatment (Supplementary Figure 1D). Recent evidence suggests that apoptosis and senescence are repressed in some tetraploid cells through epigenetic silencing of p53 target genes (Zheng et al. 2012). Indeed, MIF inhibits p53-dependent gene expression and suppresses apoptosis associated with p53 activation and redox stress (Lue et al. 2007). Nevertheless, our results are consistent with the notion that p53 is not required for mitotic cell death (Toh et al. 2010). Overall, the current findings indicate that JNK triggers a death response and that the MIF/CD74 axis is crucial in this process.

The analysis of 27 clinical specimens indicated a high level of CD74 and MIF expression and expression of downstream targets. ATC cells are naturally resistant to irradiation and chemotherapy. Because of their proficient ability to repair treatment-induced DNA damage during G2 cell-cycle arrest, unrepaired DNA damage accumulates in cells that prematurely enter mitosis, producing pleomorphic, undifferentiated, highly aggressive giant cell carcinoma cells. Via induction of JNK activity, 4-IPP proved to be extensively cytotoxic in HTC-C3 cells. In fact, a parallel increase in PARP cleavage was observed along with a strong increase in phospho-histone $\mathrm{H} 3$ signal intensity, which is a hallmark of oxidant-induced DNA damage and cell death (Tikoo et al. 2001). These results suggest cell type-dependent apoptosis induction by oxidative stress.

Our results indicate the importance of the MIF/CD74 axis in supporting tumor polyploidy. 4-IPP holds promise as a new anti-polyploid therapeutic drug, which could potentially be used to target polyploid tumor cells in thyroid cancer patients. This work demonstrates that the MIF/CD74 axis is required for continued cell proliferation of TPC- 1 and HTC-C 3 cells and that it activates AMPK even as JNK is inhibited, predisposing cells to endoreduplication. Furthermore, the cell cycle functions of MIF/CD74 axis provide important opportunities for future studies of how it conveys its anti-apoptotic activity. MIF/CD74 axis may be differentially regulated in normal vs cancer cells. If so, MIF/CD74 axis could prove to be a promising target for ATC treatment.

The current literature also supports a role for MIF in the development of obesity, chronic inflammation, and insulin resistance. As therapies targeting the MIF/CD74 pathway reach clinical development, new opportunities also may arise for the treatment of cancer. ATC remains an intractable disease with poor outcome, and this tumor type requires new therapeutic strategies. Novel therapies that specifically target polyploidization provide a new approach to inducing sustained remission and increasing overall survival. However, little is known about the sideeffects induced by blocking endoreduplication. Continued advances in our understanding of the process of polyploidization and how it differs from the proliferative cell cycle will provide additional targets for therapeutic intervention.

\section{Supplementary data}

This is linked to the online version of the paper at http://dx.doi.org/10.1530/ ERC-15-0299.

\section{Declaration of interest}

The authors declare that there is no conflict of interest that could be perceived as prejudicing the impartiality of the research reported.

Published by Bioscientifica Ltd. 


\section{Funding}

This study was supported in part by a grant from Associazione italiana per la ricerca sul cancro (AIRC) and the Italian Ministry of Public Health.

\section{Author contribution statement}

L Varinelli, D Caccia, and I Bongarzone conceived and designed the experiments. L Varinelli, D Caccia, C C Volpi, M De Bortoli, A V Gualeni, E Taverna, $V$ Leoni, and C Caccia performed the experiments. L Varinelli, D Caccia, A Gloghini, V Leoni, G Manenti, and I Bongarzone analyzed the data and provided the interpretations. L Varinelli, D Caccia, and I Bongarzone wrote the manuscript. All authors read and approved the final manuscript.

\section{Acknowledgements}

We thank Gabriella Abolafio for FACS analysis.

\section{References}

Bech-Otschir D, Seeger M \& Dubiel W 2002 The COP9 signalosome: at the interface between signal transduction and ubiquitin-dependent proteolysis. Journal of Cell Science 115 467-473.

Bucala R 2013 MIF, MIF alleles, and prospects for therapeutic intervention in autoimmunity. Journal of Clinical Immunology 33 (Suppl 1) S72-S78. (doi:10.1007/s10875-012-9781-1)

Caccia D, Miccichè F, Cassinelli G, Mondellini P, Casalini P \& Bongarzone I 2010 Dasatinib reduces FAK phosphorylation increasing the effects of RPI-1 inhibition in a RET/PTC1-expressing cell line. Molecular Cancer 9 278. (doi:10.1186/1476-4598-9-278)

Caccia D, Zanetti Domingues L, Miccichè F, De Bortoli M, Carniti C, Mondellini P \& Bongarzone I 2011 Secretome compartment is a valuable source of biomarkers for cancer-relevant pathways. Journal of Proteome Research 10 4196-4207. (doi:10.1021/pr200344n)

Calandra T \& Roger T 2003 Macrophage migration inhibitory factor: a regulator of innate immunity. Nature Reviews. Immunology 10 791-800. (doi:10.1038/nri1200)

Candido J \& Hagemann T 2013 Cancer-related inflammation. Journal of Clinical Immunology 33 (Suppl 1) S79-S84. (doi:10.1007/s10875-0129847-0)

DeLellis RA, Lloyd RV, Heitz PU \& Eng C 2004 World Health Organisation classification of tumors. Pathology and genetics of tumors of endocrine organs. Lyon, France: IARC Press.

Fingerle-Rowson G \& Petrenko O 2007 MIF coordinates the cell cycle with DNA damage checkpoints. Lessons from knockout mouse models. Cell Division 19 2-22. (doi:10.1186/1747-1028-2-22)

Gorla L, Mondellini P, Cuccuru G, Miccichè F, Cassinelli G, Cremona M, Pierotti MA, Lanzi C \& Bongarzone I 2009 Proteomics study of medullary thyroid carcinomas expressing RET germ-line mutations: identification of new signaling elements. Molecular Carcinogenesis $\mathbf{4 8}$ 220-231. (doi:10.1002/mc.20474)

Higdon JV, Delage B, Williams DE \& Dashwood RH 2007 Cruciferous vegetables and human cancer risk: epidemiologic evidence and mechanistic basis. Pharmacological Research 55 224-236. (doi:10.1016/ j.phrs.2007.01.009)

Klasen C, Ohl K, Sternkopf M, Shachar I, Schmitz C, Heussen N, Hobeika E, Levit-Zerdoun E, Tenbrock K, Reth M et al. 2014 MIF promotes B cell chemotaxis through the receptors CXCR4 and CD74 and ZAP-70 signaling. Journal of Immunology 192 5273-5284. (doi:10.4049/jimmunol.1302209)

Kleemann R, Hausser A, Geiger G, Mischke R, Burger-Kentischer A, Flieger O, Johannes FJ, Roger T, Calandra T, Kapurniotu A et al. 2000
Intracellular action of the cytokine MIF to modulate AP- 1 activity and the cell cycle through Jab1. Nature $\mathbf{4 0 8}$ 211-216. (doi:10.1038/35041591)

Kleemann R, Grell M, Mischke R, Zimmermann G \& Bernhagen J 2002 Receptor binding and cellular uptake studies of macrophage migration inhibitory factor (MIF): use of biologically active labeled MIF derivatives. Journal of Interferon \& Cytokine Research 22 351-363. (doi:10.1089/107999002753675785)

Kloos RT 2005 Papillary thyroid cancer: medical management and follow-up. Current Treatment Options in Oncology 6 323-338. (doi:10.1007/s11864-005-0036-8)

Kojic SL, Strugnell SS \& Wiseman SM 2011 Anaplastic thyroid cancer: a comprehensive review of novel therapy. Expert Review of Anticancer Therapy 11 387-402. (doi:10.1586/era.10.179)

Leng L, Metz CN, Fang Y, Xu J, Donnelly S, Baugh J, Delohery T, Chen Y, Mitchell RA \& Bucala R 2003 MIF signal transduction initiated by binding to CD74. Journal of Experimental Medicine 197 1467-1476. (doi:10.1084/jem.20030286)

Leoni V, Strittmatter L, Zorzi G, Zibordi F, Dusi S, Garavaglia B, Venco P, Caccia C, Souza AL, Deik A et al. 2012 Metabolic consequences of mitochondrial coenzyme A deficiency in patients with PANK2 mutations. Molecular Genetics and Metabolism 105 463-471. (doi:10.1016/j.ymgme.2011.12.005)

Li L, Pan R, Li R, Niemann B, Aurich AC, Chen Y \& Rohrbach S 2011 Mitochondrial biogenesis and peroxisome proliferator-activated receptor- $\gamma$ coactivator- $1 \alpha$ (PGC- $1 \alpha$ ) deacetylation by physical activity: intact adipocytokine signaling is required. Diabetes 60 157-197. (doi:10.2337/db10-0331)

Lue H, Thiele M, Franz J, Dahl E, Speckgens S, Leng L, Fingerle-Rowson G, Bucala R, Lüscher B \& Bernhagen J 2007 Macrophage migration inhibitory factor (MIF) promotes cell survival by activation of the Akt pathway and role for CSN5/JAB1 in the control of autocrine MIF activity. Oncogene 26 5046-5059. (doi:10.1038/sj.onc.1210318)

Morand EF, Leech M \& Bernhagen J 2006 MIF: a new cytokine link between rheumatoid arthritis and atherosclerosis. Nature Reviews. Drug Discovery 5 399-410. (doi:10.1038/nrd2029)

Nemajerova A, Moll UM, Petrenko O \& Fingerle-Rowson G 2007 Macrophage migration inhibitory factor coordinates DNA damage response with the proteasomal control of the cell cycle. Cell Cycle $\mathbf{6}$ 1030-1034. (doi:10.4161/cc.6.9.4163)

Qi D, Hu X, Wu X, Merk M, Leng L, Bucala R \& Young LH 2009 Cardiac macrophage migration inhibitory factor inhibits JNK pathway activation and injury duringischemia/reperfusion. Journal of Clinical Investigation 119 3807-3816. (doi:10.1172/JCI39738)

Russell RR III, Li J, Coven DL, Pypaert M, Zechner C, Palmeri M, Giordano FJ, Mu J, Birnbaum MJ \& Young LH 2004 AMP-activated protein kinase mediates ischemic glucose uptake and prevents postischemic cardiac dysfunction, apoptosis, and injury. Journal of Clinical Investigation 114 495-503. (doi:10.1172/JCI19297)

Sanchez-Niño MD, Sanz AB, Ruiz-Andres O, Poveda J, Izquierdo MC, Selgas R, Egido J \& Ortiz A 2013 MIF, CD74 and other partners in kidney disease: tales of a promiscuous couple. Cytokine \& Growth Factor Reviews 24 23-40. (doi:10.1016/j.cytogfr.2012.08.001)

Sánchez-Zamora YI \& Rodriguez-Sosa M 2014 The role of MIF in type 1 and type 2 diabetes mellitus. Journal of Diabetes Research 2014804519. (doi:10.1155/2014/804519)

Schweppe RE, Klopper JP, Korch C, Pugazhenthi U, Benezra M \& Knauf JA 2008 Deoxyribonucleic acid profiling analysis of 40 human thyroid cancer cell lines reveals cross-contamination resulting in cell line redundancy and misidentification. Journal of Clinical Endocrinology and Metabolism 93 4331-4341. (doi:10.1210/jc.2008-1102)

Shi X, Leng L, Wang T, Wang W, Du X, Li J, McDonald C, Chen Z, MurphyJW, Lolis E et al. 2006 CD44 is the signaling component of the macrophage migration inhibitory factor-CD74 receptor complex. Immunity $\mathbf{2 5}$ 595-606. (doi:10.1016/j.immuni.2006.08.020)

Startlets D, Gore Y, Binsky I, Haran M, Harpaz N, Shvidel L, Becker-Herman S, Berrebi A \& Shachar I 2006 Cell-surface CD74 initiates a signaling 
cascade leading to cell proliferation and survival. Blood 107 4807-4816. (doi:10.1182/blood-2005-11-4334)

Thiele M \& Bernhagen J 2005 Link between macrophage migration inhibitory factor and cellular redox regulation. Antioxidants \& Redox Signaling 7 9-10. (doi:10.1089/ars.2005.7.1234)

Tikoo K, Lau SS \& Monks TJ 2001 Histone H3 phosphorylation is coupled to poly-(ADP-ribosylation) during reactive oxygen species-induced cell death in renal proximal tubular epithelial cells. Molecular Pharmacology 60 394-402. (doi:10.1124/mol.60.2.394)

Toh WH, Nam SY \& Sabapathy K 2010 An essential role for p73 in regulating mitotic cell death. Cell Death and Differentiation 17 787-800. (doi:10.1038/cdd.2009.181)

Toso C, Emamaullee JA, Merani S \& Shapiro AM 2008 The role of macrophage migration inhibitory factor on glucose metabolism and diabetes. Diabetologia 51 1937-1946. (doi:10.1007/s00125-008-1063-3)

Vazquez-Martin A, Oliveras-Ferraros C, Lopez-Bonet E \& Menendez JA 2009 AMPK: evidence for an energy-sensing cytokinetic tumor suppressor. Cell Cycle 8 3679-3683. (doi:10.4161/cc.8.22.9905)
Wang J, Tong C, Yan X, Yeung E, Gandavadi S, Hare AA, Du X, Chen Y, Xiong H, Ma C et al. 2014 Limiting cardiac ischemic injury by pharmacological augmentation of macrophage migration inhibitory factor-AMP-activated protein kinase signal transduction. Circulation 128 225-236. (doi:10.1161/CIRCULATIONAHA.112. 000862)

Winner M, Meier J, Zierow S, Rendon BE, Crichlow GV \& Riggs R 2008 A novel, macrophage migration inhibitory factor suicide substrate inhibits motility and growth of lung cancer cells. Cancer Research 68 7253-7257. (doi:10.1158/0008-5472.CAN-07-6227)

Yun H, Kim HS, Lee S, Kang I, Kim SS, Choe W \& Ha J 2009 AMP kinase signaling determines whether c-Jun $\mathrm{N}$-terminal kinase promotes survival or apoptosis during glucose deprivation. Carcinogenesis 30 529-537. (doi:10.1093/carcin/bgn259)

Zheng L, Dai H, Zhou M, Li X, Liu C, Guo Z, Wu X, Wu J, Wang C, Zhong J et al. 2012 Polyploid cells rewire DNA damage response networks to overcome replication stress-induced barriers for tumour progression. Nature Communications 3 815. (doi:10.1038/ncomms1825)

Received in final form 18 June 2015

Accepted 23 July 2015

Made available online as an Accepted Preprint

23 July 2015 